\title{
Astrocyte activation and reactive gliosis-A new target in stroke?
}

\author{
Milos Pekny ${ }^{\mathrm{a}, \mathrm{c}, \mathrm{d}, *,}$ Ulrika Wilhelmsson ${ }^{\mathrm{a}}$, Turgut Tatlisumak ${ }^{\mathrm{a}, \mathrm{b}}$, Marcela Pekna ${ }^{\mathrm{a}, \mathrm{c}, \mathrm{d}}$

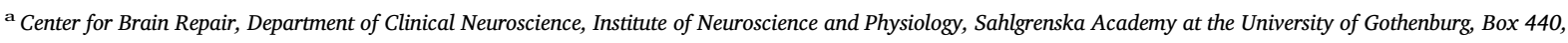 \\ 40530 Gothenburg, Sweden \\ ${ }^{\mathrm{b}}$ Department of Neurology, Sahlgrenska University Hospital, Gothenburg, Sweden \\ ${ }^{\mathrm{c}}$ Florey Institute of Neuroscience and Mental Health, Parkville, VIC, Australia \\ ${ }^{\mathrm{d}}$ University of Newcastle, Newcastle, NSW, Australia
}

\section{A R T I C L E I N F O}

\section{Keywords:}

Astrocytes

Reactive gliosis

Intermediate filaments (Nanofilaments)

GFAP

Vimentin

Nestin

Stroke

Brain ischemia

Perinatal asphyxia

The complement system

C3

C3a

Neural plasticity

Brain repair

\begin{abstract}
A B S T R A C T
Stroke is an acute insult to the central nervous system (CNS) that triggers a sequence of responses in the acute, subacute as well as later stages, with prominent involvement of astrocytes. Astrocyte activation and reactive gliosis in the acute stage of stroke limit the tissue damage and contribute to the restoration of homeostasis. Astrocytes also control many aspects of neural plasticity that is the basis for functional recovery. Here, we discuss the concept of intermediate filaments (nanofilaments) and the complement system as two handles on the astrocyte responses to injury that both present attractive opportunities for novel treatment strategies modulating astrocyte functions and reactive gliosis.
\end{abstract}

\section{Introduction}

Stroke is the second most common cause of death globally after coronary heart disease $[1,2]$. One in 6 persons will experience a stroke during his/her life and 1 in 10 will die of it $[1,2]$. The majority of stroke survivors live with serious disabilities requiring long-term assistance. Stroke care alone absorbs 5-6\% of all health expenditures making it extremely expensive [3]. Despite the magnitude of the problem, there are only very few effective treatments for stroke. Stroke is a highly heterogeneous disease (ischemic stroke i.e. brain infarction, intracerebral and subarachnoidal hemorrhage being the major subtypes, each with several distinct causes and risk factors; Fig. 1). Ischemic stroke occurs when a cerebral artery is occluded by a blood clot that is formed locally (thrombus) but more often comes from another location (embolus, e.g. from the heart or from an atherosclerotic plaque in a large proximal artery). If this occlusion is not rapidly reversed, an ischemic infarct develops due to the insufficient supply of oxygen and nutrients to the affected tissue. Intracerebral hemorrhage is caused by rupture of a cerebral artery wall and bleeding into the brain parenchyma, resulting in brain edema, brain injury and neuroinflammation. Subarachnoidal hemorrhage is caused by rupture of a cerebral artery aneurysm and bleeding into the subarachnoidal space. While ischemic stroke is most common (75-80\% of all strokes), hemorrhagic stroke is associated with high (about 50\%) mortality rate [4].

Several effective acute treatments for ischemic stroke emerged during the last decades (e.g. stroke unit care, intravenous thrombolysis, thrombectomy, or decompressive craniectomy). For subarachnoidal hemorrhage, the only effective treatment is the closure of the aneurysm after which the risk of re-bleeding is very low. Several trials with surgical interventions or drugs have failed to show clinical benefit (for a review: see [5]) and apart from supportive measures [6-8] no effective treatment exists for intracerebral hemorrhage.

Loss of function after stroke is due to both cell death in the directly damaged tissue and cell dysfunction in the surrounding as well as remote brain areas that are connected to the damaged area. Recovery of function involves reversal of dysfunction, activation of cell repair, functional reorganization within existing networks (changing the

\footnotetext{
* Corresponding author at: Center for Brain Repair, Department of Clinical Neuroscience, Institute of Neuroscience and Physiology, Sahlgrenska Academy at the University of Gothenburg, Box 440, 40530, Gothenburg, Sweden.

E-mail address: milos.pekny@neuro.gu.se (M. Pekny).
} 


\section{Ischemic stroke}

A
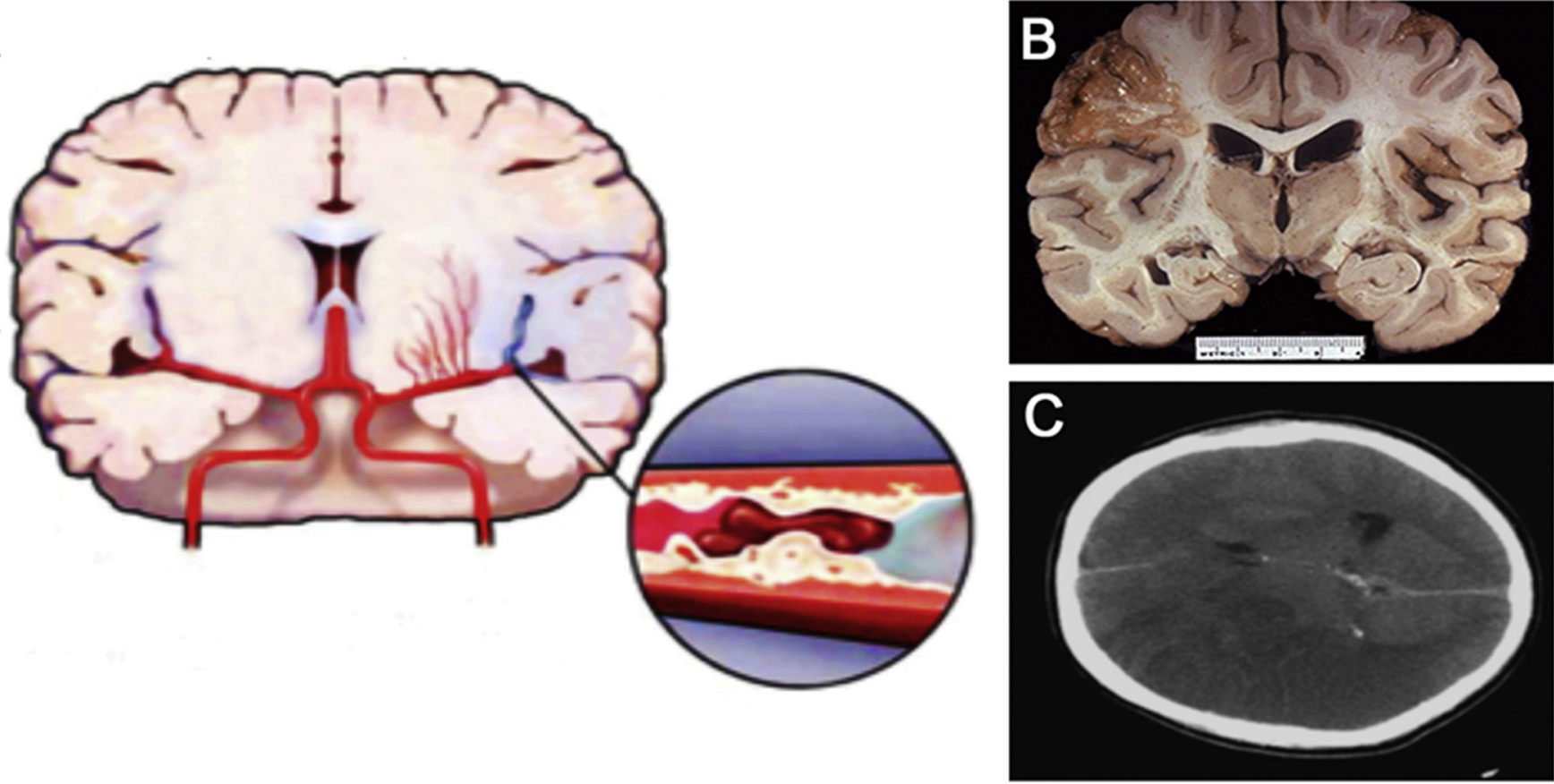

\section{Intracerebral hemorrhage}

D

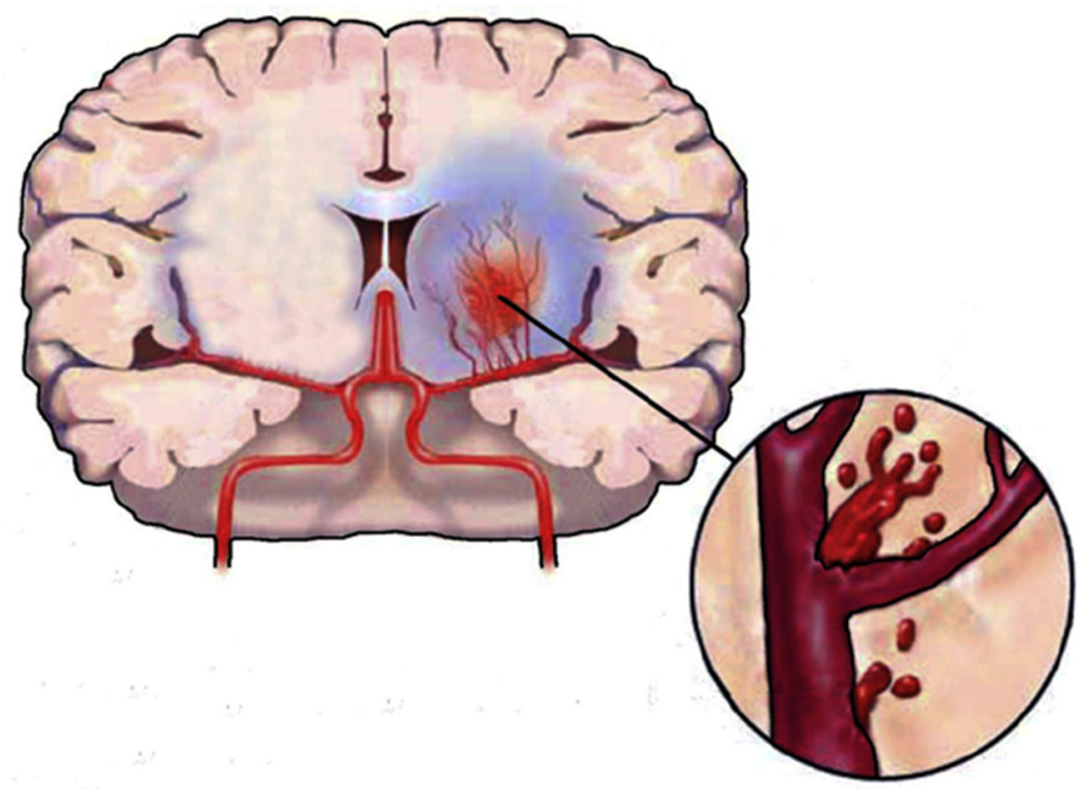

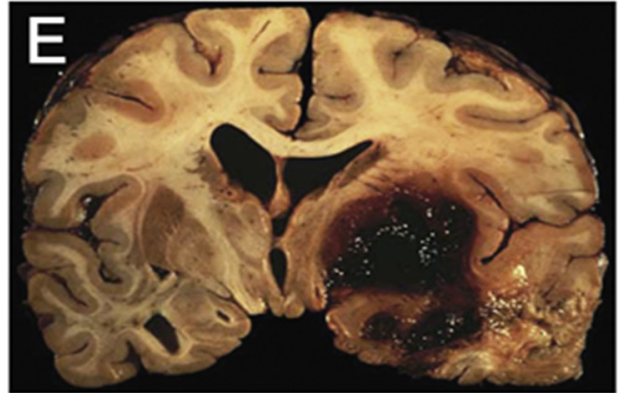

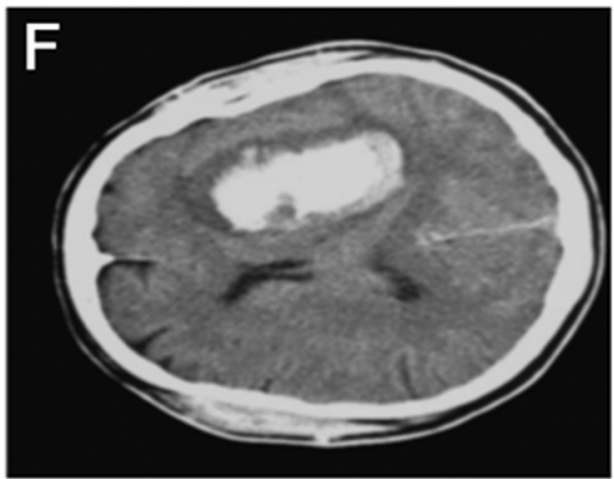

Fig. 1. Stroke is caused by either an occlusion (ischemic stroke) or rupture (hemorrhagic stroke) of a blood vessel supplying the brain with oxygen and nutrients. A-C, ischemic stroke. A, An illustration of a distal middle cerebral artery occlusion on the left side with a blood clot, leading to ischemic changes and eventually cerebral infarction. B, Human brain autopsy showing a wedge-shaped acute infarct in the middle cerebral artery territory. C, A computer tomography (CT) image of an acute infarction in the whole middle cerebral artery territory with an expansion and a midline shift. D-F, hemorrhagic stroke. D, An illustration of a deep penetrating artery rupture leading to intracerebral hematoma with surrounding edema (depicted in blue). E, Intracerebral hemorrhage in the right hemisphere of human brain autopsied a few days after the event. F, CT of a typical intracerebral hemorrhage.

properties of existing neural pathways) and neuroanatomical plasticity leading to the formation of new connections through axonal sprouting and synaptogenesis [8,9]. There is a mounting body of evidence to support the critical role of reactive astrocytes in the responses of the brain parenchyma to stroke [10-12]. In the acute phase, astrocytes limit the tissue damage and contribute to the restoration of 
A

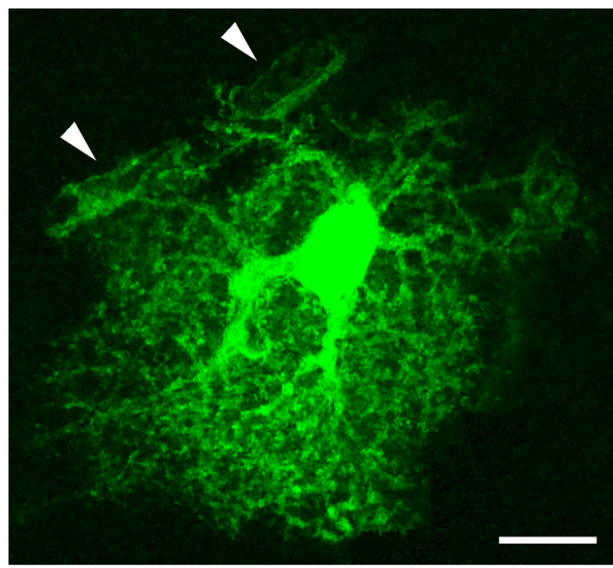

B

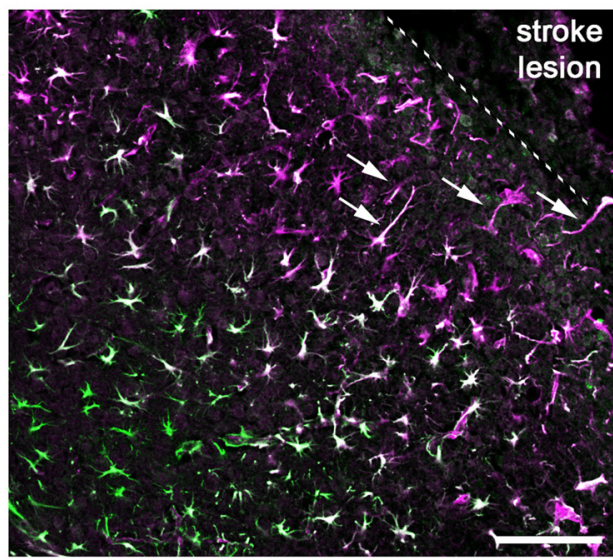

C

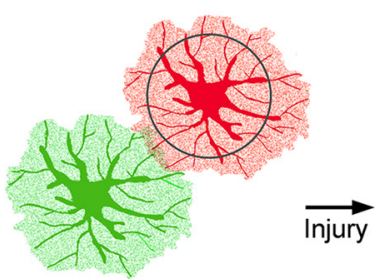

Non-reactive astrocytes

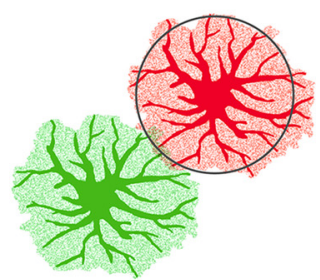

Reactive astrocytes
D

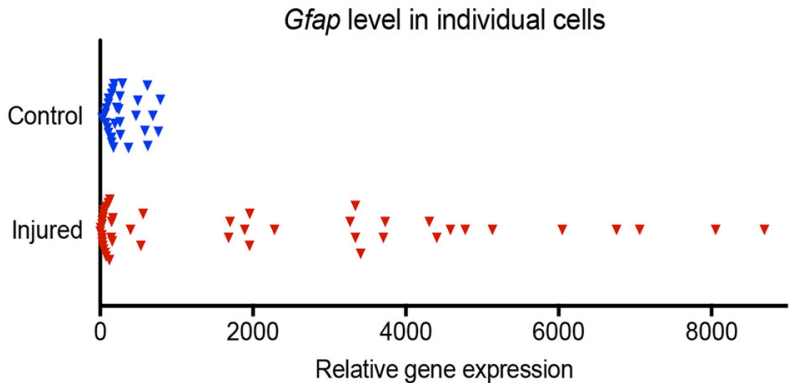

homeostasis. Given that in the post-acute and chronic phase, astrocytes seem to both facilitate and inhibit neural plasticity processes that form the basis for functional recovery, modulation of astrocyte function at this later stage appears as an interesting approach to improve the longterm outcome for stroke survivors.
Fig. 2. Astrocytes occupy distinct domains within the brain parenchyma and interact extensively with each other (forming a network, syncytium), with neuronal synapses and blood capillaries. In response to an injury, astrocytes get activated and their cellular processes become hypertrophic, however reactive astrocytes remain within their tiled domains. Reactive astrocytes surrounding the lesion area (e.g. ischemic stroke lesion) show characteristic upregulation of intermediate filament (nanofilament) proteins GFAP or nestin. Gene expression profiling of individual astrocytes shows remarkable heterogeneity of astrocytes, which becomes even more prominent within the population of astrocytes responding to an injury. A, Three-dimensional reconstruction of a dye-filled astrocyte in the dentate gyrus of the hippocampus of a mouse reveals fine astrocyte processes including those forming the astrocyte end-feet (arrowheads) that wrap around a capillary (note that no specific visualization of the capillary itself has been used here). For 3D reconstruction done for this image, see [84]. B, Four days after photothrombotic stroke lesion in the mouse cortex, reactive astrocytes within wide area around the lesion overexpress GFAP, while astrocytes directly adjacent to the lesion also express nestin. Some astrocytes characteristically extend their processes towards the lesion (arrows); picture provided by Pekny's laboratory (Drs. R. Leke and U. Wilhelmsson). C, In response to injury, the main astrocyte processes get thicker and visible over a greater distance (compare the circles and their radii), but the astrocyte domains do not get larger [41]. D, Quantification of mRNA in individual astrocytes directly isolated from uninjured hippocampus or from hippocampus of mice 4 days after unilateral enthorhinal cortex lesion shows that a difference between low and high GFAP expressing astrocytes can be $>30$-fold in uninjured situation, and $>3000$ fold in astrocyte populations that contain reactive astrocytes [82]. Green, GFAP; purple, nestin in C. Scale bar 10 and $100 \mu \mathrm{m}$ in A and B, respectively.

\section{Astrocytes and reactive gliosis}

Astrocytes control many functional aspects of CNS in health and disease, including the maintenance of the CNS homeostasis, control and support of neurons, neurotransmitter recycling, control of blood flow and the induction, functional control and removal of neuronal synapses [13-20]. The highly complex bush-like morphology with thousands of fine cellular processes, induced by interactions between astrocytic neuroligins and neuronal neurexins [20], enables the astrocyte to be in contact with neuronal synapses and form end-feet wrapping around blood capillaries as a key component of the blood brain barrier [21-23] (Fig. 2A).

In response to the physiological changes in the CNS homeostasis as well as in pathological situations, astrocytes become activated and this activation has both general and disease-specific characteristics $[12,24,25]$. In a cross-talk with microglia, astrocytes are key players in the acute and sub-acute tissue responses to injury in a response known as reactive gliosis, a term used for the activation of astroglial cells regardless of the inducing event [11,24,26,27]. Reactive astrocytes are characterized by hypertrophy of their cellular processes and show altered expression of many genes including the up-regulation of glial fibrillary acidic protein (GFAP), the main component of astrocyte cytoplasmic intermediate filaments (aka nanofilaments) (Fig. 2B). Astrocyte cytoplasmic nanofilaments are composed of GFAP, vimentin, in some cases also nestin and synemin [28-31], and are highly dynamic structures involved in cell signaling, cell migration, determine cellular viscoelastic properties in reactive glia [32] and they act as a signaling platform that controls cell stress responses, both in health and disease [29,33-36]. In their latter role, they can be viewed as a crisis command center of cells, and this function of cytoplasmic nanofilaments extends to many other cell types [24,37].

Reactive astrogliosis is a graded reaction [25,35], the most severe form being a glial scar that involves also microglia or pericytes $[32,38,39]$. Gene expression data showed that astrogliosis has both general and disease-specific components and astrocytes within the same tissue exhibit substantial heterogeneity [40].

Despite the hypertrophy of their cellular processes, reactive astrocytes in acute neurotrauma stay within their tiled domains with a 
similar extent of a minimal overlap between the adjacent astrocyte territories as seen in naïve astrocytes [41] (Fig. 2C). This is in contrast to the lost organization of astrocyte domains in animal models of epilepsy, which might reflect pathological remodeling and, interestingly, can be partially normalized by some antiepileptic drugs, e.g. valproate [42]. Aging adds additional component to this picture. On one hand, reactive gliosis, at least in some parts of the CNS, tends to increase with age [43-45], as does the territorial volume of astrocytes in a mouse neocortex and hippocampus [46]. On the other hand, some astrocytes exhibit signs of regional atrophy and functional asthenia both in the aging CNS and in some neurological diseases $[47,48]$. Thus, the astrocyte domain principle seems to be an important feature of astrocyte function, and when disturbed, may trigger or contribute to disease pathogenesis.

\section{Astrocyte responses in stroke and the astrocyte nanofilament system}

Within hours after stroke, astrocytes respond to hypoxia, neuronal cell death, release of neurotransmitters, and blood extravasation by altered expression of many genes, including those involved in STAT signaling $[49,50]$. The JAK/STAT3 signaling pathway is the main switch controlling a number of molecular and functional changes in reactive astrocytes. A number of signaling molecules, e.g. transforming growth factor (TGF)-alpha, ciliary neurotrophic factor (CNTF), interleukin (IL)-6, leukaemia inhibitory factor (LIF), or oncostatin M are known to trigger astrocyte activation [51-56]. These signaling events lead to upregulation of GFAP, vimentin and nestin, changes in cell morphology and cell proliferation [35,57]. Within days, astrocytes in the stroke penumbra proliferate and some migrate towards the infarct boarder to form a glial scar by secreting extracellular matrix (ECM) molecules. This helps to restrict the area of damage and to prevent infiltrating leukocytes from invading the healthy tissue [58,59]. Some astrocytes within the reactive boarder show a polarized morphology while astrocytes further away from the infarct show a stellate morphology (Fig. 2B).

Both ischemic and hemorrhagic stroke lead to brain edema, which can become a life-threatening condition. In cytotoxic brain edema, the lack of oxygen and glucose results in malfunction of the sodium and potassium pump in the astrocyte membrane leading to rapid swelling of the cell. The unique ability of astrocytes to respond to hypoosmotic environment by transient swelling and their tendency to assume their original cell volume [60] is called a regulatory volume decrease and involves an efflux of osmotically active molecules, e.g. taurine from astrocytes [61-63]. Regulatory volume decrease by astrocytes is a key mechanism in counteracting the development of brain edema due to ischemia or trauma, conceivably with cytoskeleton-linked stretch-activated plasma membrane channels acting as cell-volume sensors [64-67]. Indeed, intermediate-filament-fee astrocytes subjected to hypoosmotic stress exhibit about $50 \%$ reduction in taurine release compared to wild-type astrocytes [68]. In contrast, vasogenic edema is caused by rupture of a vessel and leads to a disruption of the blood brain barrier (BBB) and a direct entry of both blood cells and plasma into the extravascular space of the brain.

Astrocytes associate with, and control the function of the deep penetrating blood vessels, along which cerebrospinal and interstitial fluids are exchanged. Due to its resemblance with the lymphatic system, the term glymphatic system has been coined for this structural and functional arrangement $[69,70]$. The cerebrospinal fluid enters and the interstitial fluid leaves the brain parenchyma through the astrocyte vascular end-feet, and astrocyte Aquaporin-4 (AQP4) channels facilitate this process. The positioning of AQP4 channels in the astrocyte membrane is highly polarized towards the vascular end-feet and mice deficient in AQP4 show greatly reduced glymphatic clearance of solutes [69]. Water transport and the glymphatic brain homeostasis are highly disturbed after stroke due to the loss of APQ4 polarization in the cell membrane of reactive astrocytes [71] and mice deficient in AQP4 exhibit impaired ability to counteract vasogenic edema [72] On the other hand, other studies showed that AQP4 deletion reduced brain edema after ischemic stroke [73,74]. This suggests that the bi-directional water transport facilitated by AQP4 may be beneficial or detrimental depending on the edema type, i.e. AQP4-facilitated water transport may contribute to astrocyte swelling in the acute phase after stroke but may inhibit astrocyte uptake of extracellular fluid at a later stage.

Reactive astrocytes are thought to play a major role in the poststroke functional recovery. Reactive astrocytes in the periinfarct cortex inhibit axonal sprouting through, for example, up-regulation of the inhibitory signaling ligand Ephrin-A5 as the inhibition of ephrin-A5 after stroke promoted axonal outgrowth and functional recovery [75]. Reactive astrocytes may also inhibit the post-stroke synaptic plasticity that allows re-mapping of lost functions within the damaged tissue through an impaired function of the astrocyte GABA ( $\gamma$-aminobutyric acid) transporter GAT-3 in the periinfarct area, resulting in increased tonic neuronal inhibition. This inhibition can be abrogated by experimental treatment with specific agonist for $\alpha 5$-subunit-containing extrasynaptic GABA(A) receptors an thus provides a novel treatment strategy to promote functional recovery after stroke [76]. On the other hand, astrocyte secretion of synaptogenic thrombospondins 1 and 2 (Thbs-1/2) was increased in the penumbra of ischemic stroke in mice [15], and genetic deletion of Thbs-1/2 impaired post-stroke synaptogenesis [77]. The role of other astrocyte-derived regulators of synapse number and function, such as SPARC, Hevin, glypicans 4 and 6, Megf10 and MERTK $[18,19,78]$ in post-stroke recovery is currently unknown, as is the functional contribution to the new neurons generated from striatal astrocytes [79].

Transcriptome-wide analysis of astrocyte gene expression facilitates the understanding of the disease-specific astrocyte responses. Thus, the set of genes affected in the ischemic stroke and bacterial endotoxininduced neuroinflammation models was partially overlapping and partially unique to the respective pathology, with additional differences seen in the temporal expression pattern [80]. The possibility to assess the gene transcription on a single cell level provides unique information about the heterogeneity within the astrocyte population and forms the basis for astrocyte sub-classification.

Gene profiling of individual astrocytes in primary cultures and astrocytes in vivo revealed the diversity in expression levels in individual astrocytes and points to the existence of distinct astrocyte subpopulations $[81,82]$. For example, in the healthy hippocampus of an adult mouse, there is a 30-fold range in number of Gfap mRNA copies between individual astrocytes, but in the injured hippocampus this range increases to more than 3000-fold (Fig. 2D). We have recently identified a subpopulation of cells expressing both astrocyte and microglia-specific genes (Fig. 3). These cells with dual astrocyte/microglia molecular identity (M/A cells) are absent in the healthy mouse or human brain, but were found both in the injured mouse hippocampus and in the brains of stroke or Alzheimer's disease patients [82]. The function of these subpopulations of reactive astrocytes remains to be identified.

One approach to look into the function of reactive astrocytes in stroke and other neurological diseases is genetic ablation of astrocyte intermediate filament proteins, specifically GFAP and vimentin. The simultaneous absence of GFAP and vimentin in $\mathrm{GFAP}^{-/-} \mathrm{Vim}^{-/-}$mice results in intermediate filament-free reactive astrocytes [83] that are present in normal numbers and form normally tiled domains [84], but upon injury, do not develop the characteristic hypertrophy of their main cellular processes [41,84] and show other signs of attenuated reactive gliosis, e.g. decreased activation of Erk and c-fos [85] or less prominent upregulation of the 14-3-3 adapter proteins [86]. At the acute stage after neurotrauma, $\mathrm{GFAP}^{-/-} \mathrm{Vim}^{-1-}$ mice show slower healing and increased synaptic loss $[83,84]$, decreased resistance of the neural tissue to mechanical stress $[87,88]$, and in situations connected with neurodegeneration (Alzheimer's or Batten disease), increased neuronal damage $[89,90]$. 
A

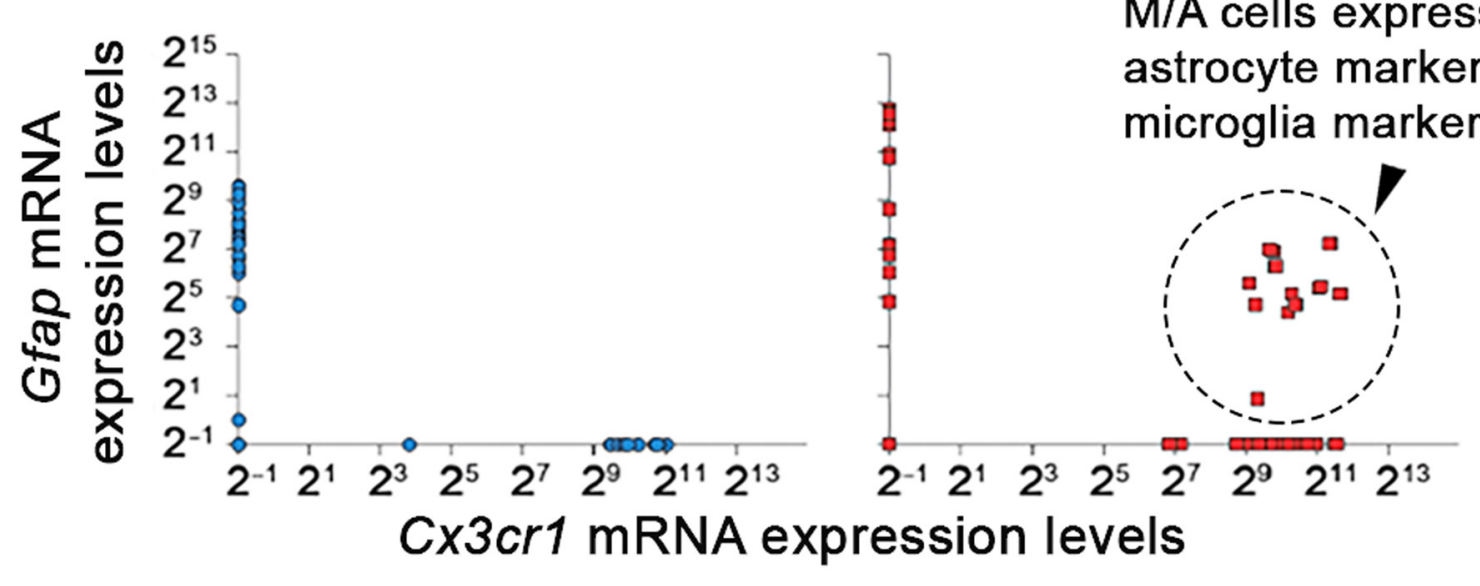

B
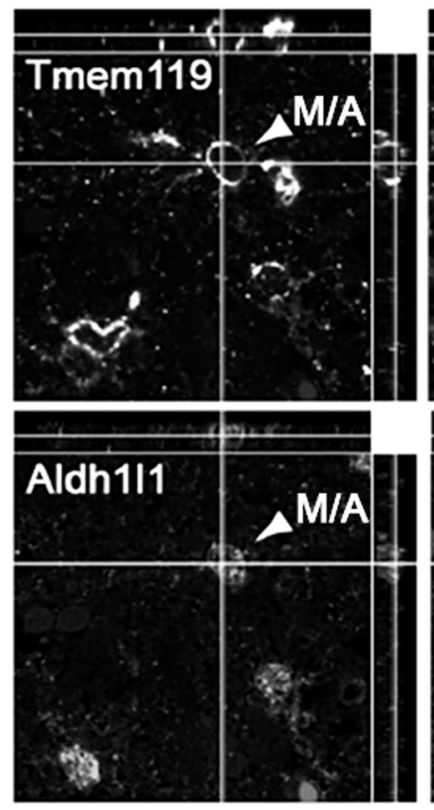
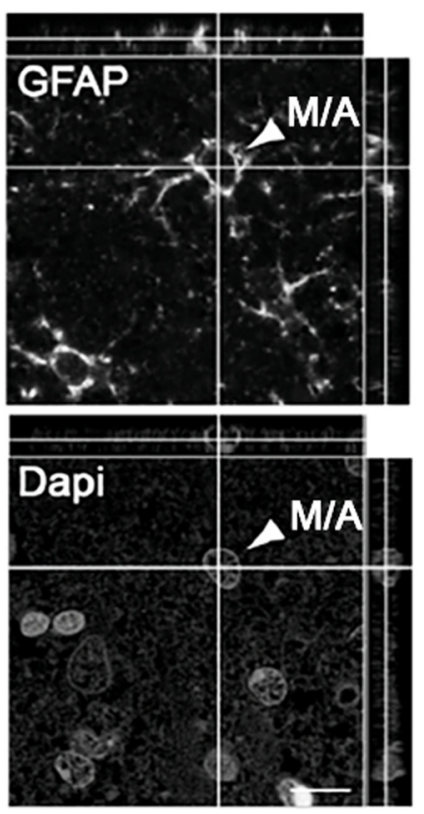

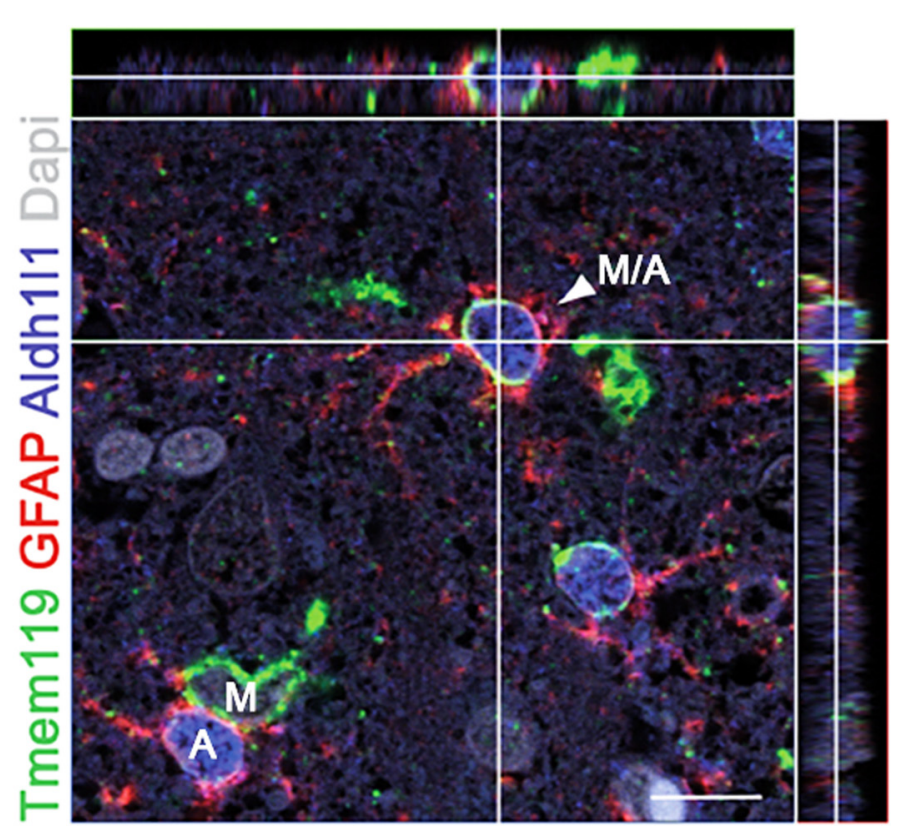

Fig. 3. Single cell gene expression profiling allows the identification of subpopulations of astrocytes, including those specific for particular disease situations. Thus, a distinct subpopulation of GFAP positive cells was found that also express makers of microglia, such as Cx3cr1, Cd68, Itgam or Aif1, showing that some cells have molecular characteristics of both astrocytes and microglia [82]. These dual identity cells (M/A cells) can be found only after experimental injury but not in naïve brains, and they were also identified in the brains of stroke and Alzheimer's disease patients [82]. A, Scatter plots showing a subpopulation of cells expressing both microglia marker Cx3cr1 and astrocyte marker Gfap in the injured mouse hippocampus. B, M/A cells positive for both astrocyte-specific (GFAP and Aldh111) and microglia-specific (Tmem119) proteins are present in the brain of stroke patients but not of healthy individuals [82]. Arrowheads, M/A cell; A, astrocyte; M, microglia. Scale bars, $10 \mu \mathrm{m}$.

Ischemic stroke induced in $G F A P^{-/-} \operatorname{Vim}^{-/-}$mice by middle cerebral artery transection results in larger infarcts, with $\mathrm{GFAP}^{-{ }^{-}} \mathrm{Vim}^{-{ }^{--}}$ astrocytes showing less efficient endothelin-3-induced blockage of gap junctional communication [10], decreased glutamine levels [91], lower total and GLT-1-mediated glutamate transport [10] and impaired response to oxidative stress [92], demonstrating that astrocyte intermediate filaments are required for the neuroprotective function of astrocytes at the acute stage of ischemic stroke. Similarly, GFAP ${ }^{-/}$ ${ }^{-}$Vim $^{-1-}$ mice exhibit lower cell survival in the inner retina after retinal ischemia-reperfusion [93]. Interestingly, the very same genetic attenuation of reactive gliosis does not affect the infarct volume in mice subjected to a photothrombotic brain injury [94], an ischemic injury model with a very limited or no ischemic penumbra [95], or tissue loss after neonatal hypoxic-ischemic brain injury [96], a model of birth asphyxia. These findings show that the intermediate filaments play a positive role in responses of astrocytes to various acute stresses. However, they also suggest that the protective effect of reactive gliosis at the acute stage after injury depends on the lesion type and may differ between developing and adult brain.

On the other hand, a number of negative effects of reactive gliosis have been documented and several disease models show that reactive gliosis may become detrimental at the later stage after injury [24,97]. Thus, the inhibition of chondroitin sulphate proteoglycans produced by astrocytes and oligodendrocyte precursors, can improve post-traumatic axonal regeneration [98-103], or ephrin-A5 produced by reactive astrocytes is known to limit axonal sprouting and functional recovery after injury [75]. Apart from its downsides at the acute stages of injury, attenuation of reactive astrogliosis in $G F A P^{-/-} \mathrm{Vim}^{-/-}$mice gives several desirable outcomes, such as better synaptic regeneration [84], better regeneration and functional recovery after spinal cord injury [104], or better regeneration of the severed optic nerve in postnatal mice [105].

Astrocytes are known to control differentiation of neural stem cells by a variety of mechanisms - via secreted factors [106-108], 
membrane-associated molecules [109], as well as through direct cellcell interactions [110]. In the adult rodent hippocampus, the newly born neurons get integrated into the existing neural circuitry [111-114], and this facilitates both the formation of new memories [115] and forgetting of the previously acquired and stored information [116]. This has important implications for both the healthy and injured brain. Interestingly, both basal [45,117], adult post-traumatic [117], and neonatal post-hypoxic/ischemic [96] hippocampal neurogenesis are increased in $\mathrm{GFAP}^{-/-} \mathrm{Vim}^{-/-}$mice, and we proposed that the negative control of neurogenesis by astrocytes via Notch signaling to neural stem cells [117,118], and intracellular vesicle trafficking in astrocytes [119-121], depend on GFAP and vimentin. In addition, the CNS niche of $\mathrm{GFAP}^{-/-} \mathrm{Vim}^{-/-}$mice supports better differentiation, integration and survival of neural grafts [122] and better neuronal and astrocyte differentiation of transplanted adult neural stem cells [123]. To what extent this results from attenuated reactive gliosis or from altered interactions between host astrocytes and the grafted cells remains to be established.

Thus, the positive roles of reactive gliosis at the acute phase of neurotrauma or ischemic injury, may, at least in some situations be counteracted by restricted regenerative potential at later stages. This opens a window of therapeutic opportunities. Can we pharmacologically target astrocyte intermediate filaments with the aim of improving outcome after brain injury or stroke? Some in vitro data already point in that direction, e.g. epoxomycin, a proteasome inhibitor, which decreases the GFAP levels in astrocytes [124], when applied to astrocyteneuron co-cultures exposed to ischemia, increases the survival of neurons without compromising the ability of astrocytes to cope with ischemic stress [125]. These data hold promise for future stroke therapies, however, the effect of treatment with epoxomycin and other compounds that affect the expression and function of intermediate filament proteins in astrocytes on functional recovery after experimental stroke remains to be investigated.

\section{Complement: a modulator of astrocyte response to injury}

Over the past decade, the complement system emerged as a critical regulator of astrocyte function, not least in the post-stroke brain. Complement is a major effector of the innate immune response. However, there is a growing body of evidence that besides its role as a first line of defense against invading pathogens, complement fulfills also a range of functions that have direct implications for normal brain development and function, and the response of brain cells to injury. Complement consists of a group of over 50 circulating and cell membrane-bound proteins. Although liver is the source of the majority of the circulating complement proteins, most complement proteins, soluble molecules and receptors alike, are also produced locally in the CNS. Here, we will focus on the astrocyte-related actions of three complement proteins, namely C1q, C3 and C5.

$\mathrm{C} 1 \mathrm{q}$ is a subunit of the $\mathrm{C} 1$ complex and a pattern recognition molecule of the classical pathway of complement activation. C1q binds antigen-bound antibodies and a range of pathogen-associated molecules, but also C-reactive protein, pentraxin-3, beta-amyloid fibrils, DNA, mitochondrial membranes and a variety of molecules exposed by apoptotic and necrotic cells (reviewed in [126]). C1q-ligand binding leads to a sequence of proteolytic activation steps and subsequent proteolytic activation of C3 that generates two fragments: smaller C3a that is released and larger $\mathrm{C} 3 \mathrm{~b}$ that binds to the activating target structure. C3a exerts it functions through C3a receptor (C3aR) whereas $\mathrm{C} 3 \mathrm{~b}$ and its derivatives, are recognized by complement receptors (CR) 1-4 on phagocytic cells and B-cells. C3b is also a component of the C3 and C5 convertase complex that proteolytically activates C3 and C5. Similar to C3, C5 activation liberates a small C5a fragment that binds to C5a receptors (C5aR1 and C5aR2), and C5b that binds to the activating target and participates in the activation of the terminal part of the complement cascade.
Astrocytes express Megf10, a scavenger receptor that binds C1q [127]. Astrocytes express also C3aR [128-130], C5aR1 [131-133], C5aR2 [134], CR3 [135]. In addition, human astrocytes were reported to express also CR1 and CR2 [136,137].

Astrocytes respond to focal brain ischemia by profound changes in gene expression [80]. It has been recently proposed that endotoxin triggered neuroinflammation, acute CNS trauma or normal aging induce a neurotoxic astrocyte phenotype $[80,138,139]$ whereas astrocytes in the post-ischemic brain were suggested to be neuroprotective $[80,139]$. Microglia-astrocyte interaction appears to play a critical role in determining the reactive astrocyte phenotype. Microglia-derived cytokines such as TNF-alpha, IL-1beta and IL-6 were shown to transform astrocytes into neuroprotective phenotype after brain trauma [140]. C1q secreted by microglia in response to LPS has been put forward as one of the signaling molecules needed for the induction of neurotoxic astrocytes [139]. However, it is not known which astrocyte receptor is needed for $\mathrm{C} 1 \mathrm{q}$ to exhibit this effect. As binding of $\mathrm{C} 1 \mathrm{q}$ to Megf10 is required for normal clearance of apoptotic cells [127], Megf10, which is predominantly expressed by astrocytes [135], is clearly a possible candidate. Microglial expression of $\mathrm{C} 1 \mathrm{q}$ is also increased with age [141], as is the astrocyte expression of Megf10 and CR3, and to a lesser degree C3 [138]. Megf10 is critical for neuronal activity dependent synapse remodelling by astrocytes [78]. In the developing CNS, astrocytes instruct neurons to tag weak synapses with C1q [142] to trigger the activation of the classical complement pathway, a process leading to synapse elimination via the C3b-microglial CR3 interaction [143,144]. The C1q and CR3-dependent phagocytosis is also of critical importance for neurodegenerative post-injury debris clearance by microglia [145].

The specific involvement of the classical pathway activation-independent C1q-Megf10 interaction in the regulation of synapse number in the developing, diseased and aging brain remains to be investigated. C1q deficiency protected neonatal mice against hypoxic-ischemic brain injury [146]. In the developing brain subjected to hypoxia-ischemia, C1q accumulates in neuronal cytosol and accelerates mitochondrial production of reactive oxygen species that in turn potentiate oxidative injury [147]. Adult mice deficient in C1q were not protected against acute tissue loss after ischemic stroke or hypoxic-ischemic brain injury [147-149]. C1q is pro-angiogenic [150], neuroprotective, and stimulates neurite outgrowth in vitro and axon regeneration in vivo [151,152]. Thus, C1q exhibits its effects on both neurons and astrocytes, these actions are under strict developmental regulation, and at least some of them are independent of complement activation.

Somewhat surprisingly, C3 was recently put forward as a marker of neurotoxic astrocytes [139], despite its absence among the top 50 genes up-regulated in LPS induced astrocytes and its up-regulation by ischemia induced astrocytes [80]. Activation of NFkappaB in astrocytes leading to secretion of $\mathrm{C} 3$ and subsequent excessive activation of neuronal C3aR in the context of Alzheimer's disease pathology impair dendritic morphology and synaptic function [153]. These findings, together with the involvement of C3b in the loss of synapses indeed point to the role of astrocyte derived C3 in neurodegeneration induced by beta amyloid. In contrast, up-regulation of C3 in astrocytes seems to be protective from early neuronal damage and loss in glaucoma [154], a condition in which C1q plays a deleterious role [155]. Thus, at least in some neurodegenerative conditions, $\mathrm{C} 1 \mathrm{q}$ and $\mathrm{C} 3$ may play independent roles. The specific involvement of astrocytes, C1q and C3 in different disease context, including secondary neurodegeneration after stroke, warrant investigation.

In transient focal cerebral ischemia, C3 deficient and C3aR antagonist pre-treated mice showed reduced infarct volume and lesser neurological impairment $24 \mathrm{~h}-7$ days after ischemia, conceivably due to decreased granulocyte infiltration and reduced oxidative stress $[149,156]$, as C3a plays a critical role in endothelial activation and leukocyte recruitment into the brain [157]. Similarly, treatment with $\mathrm{C} 3 \mathrm{aR}$ antagonist improved neurologic outcome, conceivably by 


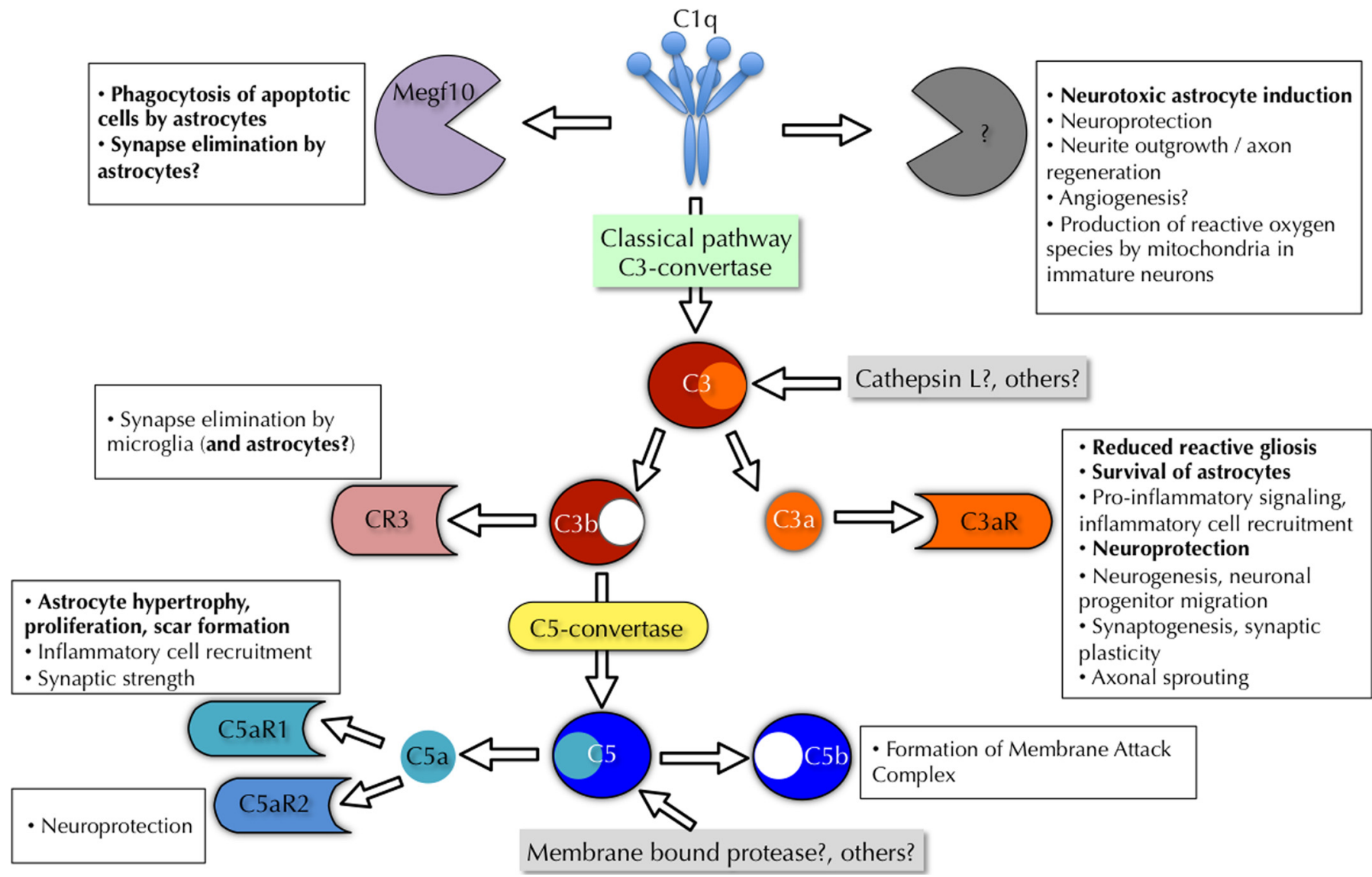

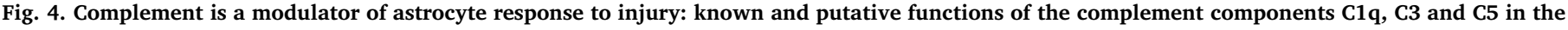

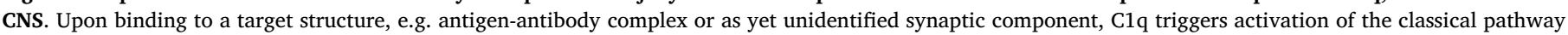

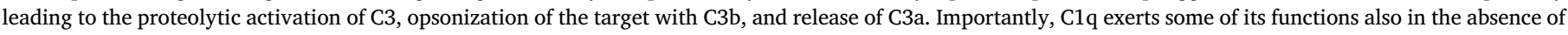

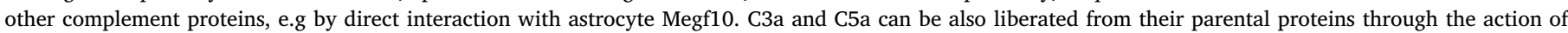

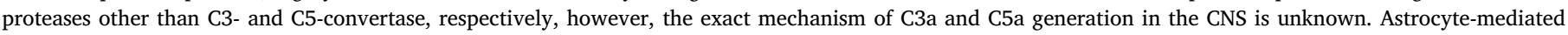
functions of C1q, C3 and C5 are shown in bold.

reducing inflammatory cell infiltration and brain edema formation after experimental intracerebral hemorrhage [158]. These results point to the deleterious effects of C3aR signaling and therapeutic benefit of systemic inhibition of C3aR signaling in the acute phase after stroke.

There is, however, also a growing body of evidence supporting the beneficial role of C3 and C3aR signaling in the ischemic brain and a potential neuroprotective role of astrocytes in this context. Ischemia leads to the up-regulation of astrocyte C3aR [130,159,160]. Astrocytes respond to C3a by changes in intracellular signaling [132] and the expression of cytokines such as interleukin (IL)-6, IL-8 and nerve growth factor (NGF) [131,161,162]. C3a promotes astrocyte survival after ischemia by inhibiting ERK signaling-mediated apoptotic pathway and caspase-3 cleavage [130]. Astrocytes are required for the neuroprotective effects of C3a in an excitotoxic environment [163]. C3a modulates also the fate of neural stem cells. C3aR signaling stimulates adult neurogenesis in mice and neuronal differentiation of mouse neural stem cells $[164,165]$, however, C3a in combination with C1q induced astroglial differentiation and migration of human neural stem cells [166]. C3/C3aR neuron-glia signaling was suggested to promote synaptic plasticity [153] but the specific mechanisms leading to C3a generation in the unchallenged healthy brain are not known.

In vivo studies provide further support for the beneficial effects of $\mathrm{C} 3 \mathrm{a} / \mathrm{C} 3 \mathrm{aR}$ after brain ischemia. Mice expressing C3a in reactive astrocytes were protected against brain tissue loss due to neonatal hypoxicischemic brain injury and single dose intraventricular injection of C3a ameliorated neonatal hypoxia-ischemia-induced memory impairment in wild type mice but not in mice lacking C3aR [167]. Intranasal treatment with C3a once daily for 3 days starting $1 \mathrm{~h}$ after hypoxiaischemia reduced injury-induced reactive gliosis in the hippocampus and improved long-term cognitive function [168]. In adult mice subjected to permanent focal cerebral ischemia, C3aR deficiency decreased whereas C3a overexpression increased the number of newly born neurons in the peri-infarct region [169], the density and size of glutamatergic pre-synaptic terminals, and presumably synapses, in the peri-infarct region as well as in the contralesional hemisphere, and the expression of GAP43, marker of axonal sprouting and plasticity [170]. GAP-43 is also upregulated during reactive synaptogenesis [171,172] and astrocyte-derived GAP-43 promotes neuronal survival and plasticity [173]. Daily intranasal treatment with C3a for 2-3 weeks led to similar positive effects on neural plasticity as well as faster and sustained functional recovery [170]. Collectively, these data provide strong evidence for the stimulatory effects of C3aR signaling on neural plasticity and recovery of function in the post-acute phase after ischemic injury to the adult brain. Given the profound differences between the immature and adult brain with regard to the role of $\mathrm{C} 1 \mathrm{q}$ [147], it is perhaps not surprising that also the response of brain cells to C3a is strongly influenced by the developmental stage. While in the adult brain signaling through neuronal C3aR modulates dendritic morphology and the function of synapses [153], C3a may exert its effects also indirectly through glial C3aR and the balance between neuronal and glial C3aR signaling may be developmentally regulated.

The finding that C5 deficiency had no effect on infarct volume after ischemic stroke [149], points to no or negligible role of C5 in brain tissue damage after ischemia. However, neurons in the CNS were 
reported to have the capability to generate C5a following ischemic stress and mice lacking C5aR1 had significantly reduced infarct volumes and improved neurological score [174]. Pre-treatment with C5aR1antagonist reduced infarct volume and improved neurological function assessed $24 \mathrm{~h}$ after transient focal brain ischemia [175]; treatment with C5aR1 antagonist alone or in combination with C3aR antagonist was neuroprotective in the acute phase after intracerebral hemorrhage [176]. Thus, acute inhibition of C5aR1 signaling appears to improve outcome after ischemic as well as hemorrhagic stroke. However, as C5a has been reported to regulate synaptic plasticity and cognitive function is severely impaired in C5aR1 deficient mice [177], prolonged C5aR1 inhibition may compromise long-term recovery. Indeed, as shown for secondary pathology and recovery after spinal cord injury, C5a/C5aR1 signaling contributes to tissue injury in the acute period but is required for optimal protective and/or reparatory astrocyte responses and glial scar formation in the post-acute phase [178]. The functions of C5aR2 in the ischemic brain are unknown, however, C5aR2 has been recently shown to convey neuroprotection in a model of traumatic spinal cord injury [179]. As C5aR2 is expressed by astrocytes, neurons as well as microglia $[134,135]$, the specific role of C5aR2 in these cell-types remains to be addressed.

Perhaps not so surprisingly, the role of C1q, C5 and C3 in the injured brain is complex and their actions are not limited to a single cell type (Fig. 4). As the effects of these proteins are highly context specific and developmentally regulated, the role of C1q, C3 and C5, their source and cellular as well as molecular mechanism of action need to be carefully determined for every pathological condition per se. While acute and short-term inhibition of C3aR and C5aR signaling seems to reduce brain tissue loss after stroke, both C3a and C5a may be needed for optimal neural plasticity and long-term functional recovery. Systemic route of administration of C3aR and C5aR1 antagonists may be preferable in the acute phase to robustly inhibit recruitment of inflammatory cells from the circulation. However, to avoid any potential adverse effects of systemic delivery of the agonists as well as to ensure their sufficient levels in the parenchyma, local routes of administration are highly desirable. Intranasal delivery of C3aR agonists seems to be an attractive approach to improve functional recovery after neonatal hypoxic-ischemic brain injury and ischemic stroke [168, 170]. Optimal therapeutic window and dose as well as the potential benefits of this type of treatment for other types of brain injuries, including hemorrhagic stroke, need to be determined by further preclinical and clinical studies.

\section{Conclusions}

The response of astrocytes to injury is a major determinant of the outcome after stroke. In the acute phase, reactive astrocytes are neuroprotective, however, in the post-acute and chronic phase, they act as both positive and negative regulators of neural plasticity, including generation of new neurons, axonal sprouting, and control of synapse number and function. Modulation of astrocyte function at this later stage, enhancing the neural plasticity promoting functions and decreasing the ones that hamper recovery, might be an attractive strategy to improve functional outcome. Astrocyte intermediate filament proteins may represent the right target for this objective and the complement system may be at least one of the suitable bullets to hit it.

\section{Acknowledgments}

The authors' research has been supported by the Swedish Medical Research Council (2017-02255 and 2017-00991), ALF Gothenburg (146051 and 716591), AFA Research Foundation, Söderbergs Foundations, Sten A. Olsson Foundation for Research and Culture, Hjärnfonden, Hagströmer's Foundation Millennium, Amlöv's Foundation, E. Jacobson's Donation Fund, VINNOVA, the Swedish Stroke Foundation, NanoNet COST Action (BM1002), and EU FP 7 Program TargetBraIn (279017).

\section{References}

[1] V.L. Feigin, C.M. Lawes, D.A. Bennett, S.L. Barker-Collo, V. Parag, Worldwide stroke incidence and early case fatality reported in 56 population-based studies: a systematic review, Lancet Neurol. 8 (2009) 355-369.

[2] R. Lozano, M. Naghavi, K. Foreman, S. Lim, K. Shibuya, V. Aboyans, et al., Global and regional mortality from 235 causes of death f or 20 age groups in 1990 and 2010: a systematic analysis f or the Global Burden of Disease Study 2010, Lancet 380 (2012) 2095-2128.

[3] A. Gustavsson, M. Svensson, F. Jacobi, C. Allgulander, J. Alonso, E. Beghi, R. Dodel, M. Ekman, C. Faravelli, L. Fratiglioni, B. Gannon, D.H. Jones, P. Jennum, A. Jordanova, L. Jonsson, K. Karampampa, M. Knapp, G. Kobelt, T. Kurth, R. Lieb, M. Linde, C. Ljungcrantz, A. Maercker, B. Melin, M. Moscarelli, A. Musayev, F. Norwood, M. Preisig, M. Pugliatti, J. Rehm, L. Salvador-Carulla, B. Schlehofer, R. Simon, H.C. Steinhausen, L.J. Stovner, J.M. Vallat, P. Van den Bergh, J. van Os, P. Vos, W. Xu, H.U. Wittchen, B. Jonsson, J. Olesen, C.D. Group, Cost of disorders of the brain in Europe 2010, Eur. Neuropsychopharmacol. 21 (2011) 718-779.

[4] C.J. van Asch, M.J. Luitse, G.J. Rinkel, I. van der Tweel, A. Algra, C.J. Klijn, Incidence, case fatality, and functional outcome of intracerebral haemorrhage over time, according to age, sex, and ethnic origin: a systematic review and metaanalysis, Lancet Neurol. 9 (2010) 167-176.

[5] T. Steiner, R. Al-Shahi Salman, R. Beer, H. Christensen, C. Cordonnier, L. Csiba, M. Forsting, S. Harnof, C.J. Klijn, D. Krieger, A.D. Mendelow, C. Molina, J. Montaner, K. Overgaard, J. Petersson, R.O. Roine, E. Schmutzhard, K. Schwerdtfeger, C. Stapf, T. Tatlisumak, B.M. Thomas, D. Toni, A. Unterberg, M. Wagner, O. European Stroke, European Stroke Organisation (ESO) guidelines for the management of spontaneous intracerebral hemorrhage, Int. J. Stroke 9 (2014) 840-855.

[6] L. Bunketorp-Käll, Å. Lundgren-Nilsson, H. Samuelsson, T. Pekny, K. Blomvé, M. Pekna, M. Pekny, C. Blomstrand, M. Nilsson, Long-term improvements after multimodal rehabilitation in late phase after stroke: a randomized controlled trial, Stroke 48 (2017) 1916.

[7] M. Nilsson, M. Pekny, Enriched environment and astrocytes in central nervous system regeneration, J. Rehabil. Med. 39 (2007) 345-352.

[8] M. Pekna, M. Pekny, M. Nilsson, Modulation of neural plasticity as a basis for stroke rehabilitation, Stroke 43 (2012) 2819-2828.

[9] T. Wieloch, K. Nikolich, Mechanisms of neural plasticity following brain injury, Curr. Opin. Neurobiol. 16 (2006) 258-264.

[10] L. Li, A. Lundkvist, D. Andersson, U. Wilhelmsson, N. Nagai, A.C. Pardo, C. Nodin, A. Stahlberg, K. Aprico, K. Larsson, T. Yabe, L. Moons, A. Fotheringham, I. Davies, P. Carmeliet, J.P. Schwartz, M. Pekna, M. Kubista, F. Blomstrand, N. Maragakis, M. Nilsson, M. Pekny, Protective role of reactive astrocytes in brain ischemia, J. Cereb. Blood Flow Metab. 28 (2008) 468-481.

[11] M. Pekny, M. Nilsson, Astrocyte activation and reactive gliosis, Glia 50 (2005) 427-434.

[12] M. Pekny, M. Pekna, A. Messing, C. Steinhauser, J.M. Lee, V. Parpura, E.M. Hol, M.V. Sofroniew, A. Verkhratsky, Astrocytes: a central element in neurological diseases, Acta Neuropathol. 131 (2016) 323-345.

[13] R.C. Koehler, R.J. Roman, D.R. Harder, Astrocytes and the regulation of cerebral blood flow, Trends Neurosci. 32 (2009) 160-169.

[14] S.J. Mulligan, B.A. MacVicar, Calcium transients in astrocyte endfeet cause cerebrovascular constrictions, Nature 431 (2004) 195-199.

[15] K.S. Christopherson, E.M. Ullian, C.C. Stokes, C.E. Mullowney, J.W. Hell, A. Agah, J. Lawler, D.F. Mosher, P. Bornstein, B.A. Barres, Thrombospondins are astrocytesecreted proteins that promote CNS synaptogenesis, Cell 120 (2005) 421-433.

[16] C. Eroglu, B.A. Barres, Regulation of synaptic connectivity by glia, Nature 468 (2010) 223-231.

[17] E.M. Ullian, S.K. Sapperstein, K.S. Christopherson, B.A. Barres, Control of synapse number by glia, Science 291 (2001) 657-661.

[18] N.J. Allen, M.L. Bennett, L.C. Foo, G.X. Wang, C. Chakraborty, S.J. Smith, B.A. Barres, Astrocyte glypicans 4 and 6 promote formation of excitatory synapses via GluA1 AMPA receptors, Nature 486 (2012) 410-414.

[19] H. Kucukdereli, N.J. Allen, A.T. Lee, A. Feng, M.I. Ozlu, L.M. Conatser, C. Chakraborty, G. Workman, M. Weaver, E.H. Sage, B.A. Barres, C. Eroglu, Control of excitatory CNS synaptogenesis by astrocyte-secreted proteins Hevin and SPARC, Proc. Natl. Acad. Sci. U. S. A. 108 (2011) E440-449.

[20] J.A. Stogsdill, J. Ramirez, D. Liu, Y.H. Kim, K.T. Baldwin, E. Enustun, T. Ejikeme, R.R. Ji, C. Eroglu, Astrocytic neuroligins control astrocyte morphogenesis and synaptogenesis, Nature 551 (2017) 192-197.

[21] E.A. Bushong, M.E. Martone, Y.Z. Jones, M.H. Ellisman, Protoplasmic astrocytes in CA1 stratum radiatum occupy separate anatomical domains, J. Neurosci. 22 (2002) 183-192.

[22] C. Iadecola, M. Nedergaard, Glial regulation of the cerebral microvasculature, Nat. Neurosci. 10 (2007) 1369-1376.

[23] A. Verkhratsky, M. Nedergaard, Physiology of Astroglia, Physiol. Rev. 98 (2018) 239-389.

[24] M. Pekny, M. Pekna, Reactive gliosis in the pathogenesis of CNS diseases, Biochim. Biophys. Acta 1862 (2016) 483-491.

[25] M.V. Sofroniew, H.V. Vinters, Astrocytes: biology and pathology, Acta Neuropathol. 119 (2010) 7-35.

[26] M.V. Sofroniew, Molecular dissection of reactive astrogliosis and glial scar formation, Trends Neurosci. 32 (2009) 638-647.

[27] A. Buffo, C. Rolando, S. Ceruti, Astrocytes in the damaged brain: molecular and cellular insights into their reactive response and healing potential, Biochem. Pharmacol. 79 (2010) 77-89. 
[28] C. Eliasson, C. Sahlgren, C.H. Berthold, J. Stakeberg, J.E. Celis, C. Betsholtz, J.E. Eriksson, M. Pekny, Intermediate filament protein partnership in astrocytes, J. Biol. Chem. 274 (1999) 23996-24006.

[29] E.M. Hol, M. Pekny, Glial fibrillary acidic protein (GFAP) and the astrocyte intermediate filament system in diseases of the central nervous system, Curr. Opin. Cell Biol. 32 (2015) 121-130.

[30] R. Jing, U. Wilhelmsson, W. Goodwill, L. Li, Y. Pan, M. Pekny, O. Skalli, Synemin is expressed in reactive astrocytes in neurotrauma and interacts differentially with vimentin and GFAP intermediate filament networks, J. Cell Sci. 120 (2007) 1267-1277.

[31] T. Pekny, M. Faiz, U. Wilhelmsson, M.A. Curtis, R. Matej, O. Skalli, M. Pekny, Synemin is expressed in reactive astrocytes and Rosenthal fibers in Alexander disease, APMIS (2013).

[32] Y.B. Lu, I. Iandiev, M. Hollborn, N. Korber, E. Ulbricht, P.G. Hirrlinger, T. Pannicke, E.Q. Wei, A. Bringmann, H. Wolburg, U. Wilhelmsson, M. Pekny, P. Wiedemann, A. Reichenbach, J.A. Kas, Reactive glial cells: increased stiffness correlates with increased intermediate filament expression, FASEB J. 25 (2011) 624-631.

[33] J.E. Eriksson, T. Dechat, B. Grin, B. Helfand, M. Mendez, H.M. Pallari, R.D. Goldman, Introducing intermediate filaments: from discovery to disease, J. Clin. Invest. 119 (2009) 1763-1771.

[34] H.M. Pallari, J.E. Eriksson, Intermediate filaments as signaling platforms, Sci. STKE 2006 (2006) pe53.

[35] M. Pekny, M. Pekna, Astrocyte reactivity and reactive astrogliosis: costs and benefits, Physiol. Rev. 94 (2014) 1077-1098.

[36] E.A. Lepekhin, C. Eliasson, C.H. Berthold, V. Berezin, E. Bock, M. Pekny, Intermediate filaments regulate astrocyte motility, J. Neurochem. 79 (2001) 617-625.

[37] M. Pekny, E.B. Lane, Intermediate filaments and stress, Exp. Cell. Res. 313 (2007) $2244-2254$

[38] C. Goritz, D.O. Dias, N. Tomilin, M. Barbacid, O. Shupliakov, J. Frisen, A pericyte origin of spinal cord scar tissue, Science 333 (2011) 238-242.

[39] M. Pekny, U. Wilhelmsson, M. Pekna, The dual role of astrocyte activation and reactive gliosis, Neurosci. Lett. 565 (2014) 30-38.

[40] Y. Zhang, B.A. Barres, Astrocyte heterogeneity: an underappreciated topic in neurobiology, Curr. Opin. Neurobiol. 20 (2010) 588-594.

[41] U. Wilhelmsson, E.A. Bushong, D.L. Price, B.L. Smarr, V. Phung, M. Terada, M.H. Ellisman, M. Pekny, Redefining the concept of reactive astrocytes as cells that remain within their unique domains upon reaction to injury, Proc. Natl. Acad. Sci. U. S. A. 103 (2006) 17513-17518.

[42] N.A. Oberheim, G.F. Tian, X. Han, W. Peng, T. Takano, B. Ransom, M. Nedergaard, Loss of astrocytic domain organization in the epileptic brain, J. Neurosci. 28 (2008) 3264-3276.

[43] J.P. David, F. Ghozali, C. Fallet-Bianco, A. Wattez, S. Delaine, B. Boniface, C. Di Menza, A. Delacourte, Glial reaction in the hippocampal formation is highly correlated with aging in human brain, Neurosci. Lett. 235 (1997) 53-56.

[44] J.R. Goss, C.E. Finch, D.G. Morgan, Age-related changes in glial fibrillary acidic protein mRNA in the mouse brain, Neurobiol. Aging 12 (1991) 165-170.

[45] A. Larsson, U. Wilhelmsson, M. Pekna, M. Pekny, Increased cell proliferation and neurogenesis in the hippocampal dentate gyrus of old GFAP(-/-)Vim(-/-) mice, Neurochem. Res. 29 (2004) 2069-2073.

[46] A. Grosche, J. Grosche, M. Tackenberg, D. Scheller, G. Gerstner, A. Gumprecht, T. Pannicke, P.G. Hirrlinger, U. Wilhelmsson, K. Huttmann, W. Hartig, C. Steinhauser, M. Pekny, A. Reichenbach, Versatile and simple approach to determine astrocyte territories in mouse neocortex and hippocampus, PLoS One 8 (2013) e69143.

[47] A. Verkhratsky, V. Parpura, Astrogliopathology in neurological, neurodevelopmental and psychiatric disorders, Neurobiol. Dis. 85 (2016) 254-261.

[48] A. Verkhratsky, R. Zorec, J.J. Rodriguez, V. Parpura, Astroglia dynamics in ageing and Alzheimer's disease, Curr. Opin. Pharmacol. 26 (2016) 74-79.

[49] J.S. Choi, S.Y. Kim, J.H. Cha, Y.S. Choi, K.W. Sung, S.T. Oh, O.N. Kim, J.W. Chung, M.H. Chun, S.B. Lee, M.Y. Lee, Upregulation of gp130 and STAT3 activation in the rat hippocampus following transient forebrain ischemia, Glia 41 (2003) 237-246.

[50] C. Justicia, C. Gabriel, A.M. Planas, Activation of the JAK/STAT pathway following transient focal cerebral ischemia: signaling through Jak1 and Stat3 in astrocytes, Glia 30 (2000) 253-270.

[51] V. Balasingam, T. Tejada-Berges, E. Wright, R. Bouckova, V.W. Yong, Reactive astrogliosis in the neonatal mouse brain and its modulation by cytokines, $\mathrm{J}$. Neurosci. 14 (1994) 846-856.

[52] S. Hostenbach, M. Cambron, M. D'Haeseleer, R. Kooijman, J. De Keyser, Astrocyte loss and astrogliosis in neuroinflammatory disorders, Neurosci. Lett. 565 (2014) $39-41$.

[53] M.A. Klein, J.C. Moller, L.L. Jones, H. Bluethmann, G.W. Kreutzberg, G. Raivich, Impaired neuroglial activation in interleukin-6 deficient mice, Glia 19 (1997) 227-233.

[54] A.G. Rabchevsky, J.M. Weinitz, M. Coulpier, C. Fages, M. Tinel, M.P. Junier, A role for transforming growth factor alpha as an inducer of astrogliosis, J. Neurosci. 18 (1998) 10541-10552.

[55] K. Sriram, S.A. Benkovic, M.A. Hebert, D.B. Miller, J.P. O'Callaghan, Induction of gp130-related cytokines and activation of JAK2/STAT3 pathway in astrocytes precedes up-regulation of glial fibrillary acidic protein in the 1-methyl-4-phenyl1,2,3,6-tetrahydropyridine model of neurodegeneration: key signaling pathway for astrogliosis in vivo? J. Biol. Chem. 279 (2004) 19936-19947.

[56] C.G. Winter, Y. Saotome, S.W. Levison, D. Hirsh, A role for ciliary neurotrophic factor as an inducer of reactive gliosis, the glial response to central-nervous-system injury, Proc. Natl. Acad. Sci. U. S. A. 92 (1995) 5865-5869.
[57] S. Bardehle, M. Kruger, F. Buggenthin, J. Schwausch, J. Ninkovic, H. Clevers, H.J. Snippert, F.J. Theis, M. Meyer-Luehmann, I. Bechmann, L. Dimou, M. Gotz, Live imaging of astrocyte responses to acute injury reveals selective juxtavascular proliferation, Nat. Neurosci. 16 (2013) 580-586.

[58] T.G. Bush, N. Puvanachandra, C.H. Horner, A. Polito, T. Ostenfeld, C.N. Svendsen, L. Mucke, M.H. Johnson, M.V. Sofroniew, Leukocyte infiltration, neuronal degeneration, and neurite outgrowth after ablation of scar-forming, reactive astrocytes in adult transgenic mice, Neuron 23 (1999) 297-308.

[59] D.J. Myer, G.G. Gurkoff, S.M. Lee, D.A. Hovda, M.V. Sofroniew, Essential protective roles of reactive astrocytes in traumatic brain injury, Brain 129 (2006) $2761-2772$.

[60] H.K. Kimelberg, Swelling and volume control in brain astroglial cells, in: H.E.K. Gilles, R. Bolis L (Eds.), Advances in Comparative and Environmental Physiology, Vol. 9 Springer, New York, 1991.

[61] J. Moran, T. Maar, H. Pasantes-Morales, Cell volume regulation in taurine deficient cultured astrocytes, Adv. Exp. Med. Biol. 359 (1994) 361-367.

[62] H. Pasantes-Morales, J. Moran, A. Schousboe, Volume-sensitive release of taurine from cultured astrocytes: properties and mechanism, Glia 3 (1990) 427-432.

[63] D. Vitarella, D.J. DiRisio, H.K. Kimelberg, M. Aschner, Potassium and taurine release are highly correlated with regulatory volume decrease in neonatal primary rat astrocyte cultures, J. Neurochem. 63 (1994) 1143-1149.

[64] H.F. Cantiello, Role of actin filament organization in cell volume and ion channel regulation, J. Exp. Zool. 279 (1997) 425-435.

[65] H.F. Cantiello, A.G. Prat, J.V. Bonventre, C.C. Cunningham, J.H. Hartwig, D.A. Ausiello, Actin-binding protein contributes to cell volume regulatory ion channel activation in melanoma cells, J. Biol. Chem. 268 (1993) 4596-4599.

[66] J. Moran, M. Sabanero, I. Meza, H. Pasantes-Morales, Changes of actin cytoskeleton during swelling and regulatory volume decrease in cultured astrocytes, Am. J. Physiol. 271 (1996) C1901-1907.

[67] R. Sanchez-Olea, J. Moran, A. Schousboe, H. Pasantes-Morales, Hyposmolarityactivated fluxes of taurine in astrocytes are mediated by diffusion, Neurosci. Lett. 130 (1991) 233-236.

[68] M. Ding, C. Eliasson, C. Betsholtz, A. Hamberger, M. Pekny, Altered taurine release following hypotonic stress in astrocytes from mice deficient for GFAP and vimentin, Brain Res. Mol. Brain Res. 62 (1998) 77-81.

[69] J.J. Iliff, M. Wang, Y. Liao, B.A. Plogg, W. Peng, G.A. Gundersen, H. Benveniste, G.E. Vates, R. Deane, S.A. Goldman, E.A. Nagelhus, M. Nedergaard, A paravascular pathway facilitates CSF flow through the brain parenchyma and the clearance of interstitial solutes, including amyloid beta, Sci. Transl. Med. 4 (2012) 147ra111.

[70] B.A. Plog, M. Nedergaard, The glymphatic system in central nervous system health and disease: past, present, and future, Annu. Rev. Pathol. 13 (2018) 379-394.

[71] E. Steiner, G.U. Enzmann, S. Lin, S. Ghavampour, M.J. Hannocks, B. Zuber, M.A. Ruegg, L. Sorokin, B. Engelhardt, Loss of astrocyte polarization upon transient focal brain ischemia as a possible mechanism to counteract early edema formation, Glia 60 (2012) 1646-1659.

[72] M.C. Papadopoulos, G.T. Manley, S. Krishna, A.S. Verkman, Aquaporin-4 facilitates reabsorption of excess fluid in vasogenic brain edema, FASEB J. 18 (2004) 1291-1293.

[73] N.N. Haj-Yasein, G.F. Vindedal, M. Eilert-Olsen, G.A. Gundersen, O. Skare, P. Laake, A. Klungland, A.E. Thoren, J.M. Burkhardt, O.P. Ottersen, E.A. Nagelhus, Glial-conditional deletion of aquaporin-4 (Aqp4) reduces blood-brain water uptake and confers barrier function on perivascular astrocyte endfeet, Proc. Natl. Acad. Sci. U. S. A. 108 (2011) 17815-17820.

[74] G.T. Manley, M. Fujimura, T. Ma, N. Noshita, F. Filiz, A.W. Bollen, P. Chan, A.S. Verkman, Aquaporin-4 deletion in mice reduces brain edema after acute water intoxication and ischemic stroke, Nat. Med. 6 (2000) 159-163.

[75] J.J. Overman, A.N. Clarkson, I.B. Wanner, W.T. Overman, I. Eckstein, J.L. Maguire, I.D. Dinov, A.W. Toga, S.T. Carmichael, A role for ephrin-A5 in axonal sprouting, recovery, and activity-dependent plasticity after stroke, Proc. Natl. Acad. Sci. U. S. A. 109 (2012) E2230-2239.

[76] A.N. Clarkson, B.S. Huang, S.E. Macisaac, I. Mody, S.T. Carmichael, Reducing excessive GABA-mediated tonic inhibition promotes functional recovery after stroke, Nature 468 (2010) 305-309.

[77] J. Liauw, S. Hoang, M. Choi, C. Eroglu, M. Choi, G.H. Sun, M. Percy, B. WildmanTobriner, T. Bliss, R.G. Guzman, B.A. Barres, G.K. Steinberg, Thrombospondins 1 and 2 are necessary for synaptic plasticity and functional recovery after stroke, $\mathrm{J}$. Cereb. Blood Flow Metab. 28 (2008) 1722-1732.

[78] W.S. Chung, L.E. Clarke, G.X. Wang, B.K. Stafford, A. Sher, C. Chakraborty, J. Joung, L.C. Foo, A. Thompson, C. Chen, S.J. Smith, B.A. Barres, Astrocytes mediate synapse elimination through MEGF10 and MERTK pathways, Nature 504 (2013) 394-400.

[79] J.P. Magnusson, C. Goritz, J. Tatarishvili, D.O. Dias, E.M. Smith, O. Lindvall, Z. Kokaia, J. Frisen, A latent neurogenic program in astrocytes regulated by Notch signaling in the mouse, Science 346 (2014) 237-241.

[80] J.L. Zamanian, L. Xu, L.C. Foo, N. Nouri, L. Zhou, R.G. Giffard, B.A. Barres, Genomic analysis of reactive astrogliosis, J. Neurosci. 32 (2012) 6391-6410.

[81] A. Stahlberg, D. Andersson, J. Aurelius, M. Faiz, M. Pekna, M. Kubista, M. Pekny, Defining cell populations with single-cell gene expression profiling: correlations and identification of astrocyte subpopulations, Nucleic Acids Res. 39 (2011) e24.

[82] U. Wilhelmsson, D. Andersson, Y. de Pablo, R. Pekny, A. Ståhlberg, J. Mulder, N. Mitsios, T. Hortobágyi, M. Pekny, M. Pekna, Injury leads to the appearance of cells with characteristics of both microglia and astrocytes in mouse and human brain, Cereb. Cortex 27 (2017) 3360-3377.

[83] M. Pekny, C.B. Johansson, C. Eliasson, J. Stakeberg, A. Wallen, T. Perlmann, U. Lendahl, C. Betsholtz, C.H. Berthold, J. Frisen, Abnormal reaction to central nervous system injury in mice lacking glial fibrillary acidic protein and vimentin, 
J. Cell Biol. 145 (1999) 503-514.

84] U. Wilhelmsson, L. Li, M. Pekna, C.H. Berthold, S. Blom, C. Eliasson, O. Renner, E. Bushong, M. Ellisman, T.E. Morgan, M. Pekny, Absence of glial fibrillary acidic protein and vimentin prevents hypertrophy of astrocytic processes and improves post-traumatic regeneration, J. Neurosci. 24 (2004) 5016-5021.

[85] T. Nakazawa, M. Takeda, G.P. Lewis, K.S. Cho, J. Jiao, U. Wilhelmsson, S.K. Fisher, M. Pekny, D.F. Chen, J.W. Miller, Attenuated glial reactions and photoreceptor degeneration after retinal detachment in mice deficient in glial fibrillary acidic protein and vimentin, Invest. Ophthalmol. Vis. Sci. 48 (2007) 2760-2768.

[86] C. Sihlbom, U. Wilhelmsson, L. Li, C.L. Nilsson, M. Pekny, 14-3-3 expression in denervated hippocampus after entorhinal cortex lesion assessed by culture-derived isotope tags in quantitative proteomics, J. Proteome Res. 6 (2007) 3491-3500.

[87] A. Lundkvist, A. Reichenbach, C. Betsholtz, P. Carmeliet, H. Wolburg, M. Pekny, Under stress, the absence of intermediate filaments from Muller cells in the retina has structural and functional consequences, J. Cell Sci. 117 (2004) 3481-3488.

[88] M.R. Verardo, G.P. Lewis, M. Takeda, K.A. Linberg, J. Byun, G. Luna, U. Wilhelmsson, M. Pekny, D.F. Chen, S.K. Fisher, Abnormal reactivity of muller cells after retinal detachment in mice deficient in GFAP and vimentin, Invest. Ophthalmol. Vis. Sci. 49 (2008) 3659-3665.

[89] A.W. Kraft, X. Hu, H. Yoon, P. Yan, Q. Xiao, Y. Wang, S.C. Gil, J. Brown, U. Wilhelmsson, J.L. Restivo, J.R. Cirrito, D.M. Holtzman, J. Kim, M. Pekny, J.M. Lee, Attenuating astrocyte activation accelerates plaque pathogenesis in APP/ PS1 mice, FASEB J. 27 (2013) 187-198.

[90] S.L. Macauley, M. Pekny, M.S. Sands, The role of attenuated astrocyte activation in infantile neuronal ceroid lipofuscinosis, J. Neurosci. 31 (2011) 15575-15585.

[91] M. Pekny, C. Eliasson, R. Siushansian, M. Ding, S.J. Dixon, M. Pekna, J.X. Wilson, A. Hamberger, The impact of genetic removal of GFAP and/or vimentin on glutamine levels and transport of glucose and ascorbate in astrocytes, Neurochem. Res. 24 (1999) 1357-1362.

[92] Y. de Pablo, M. Nilsson, M. Pekna, M. Pekny, Intermediate filaments are important for astrocyte response to oxidative stress induced by oxygen-glucose deprivation and reperfusion, Histochem. Cell Biol. 140 (2013) 81-91.

[93] K.A. Wunderlich, N. Tanimoto, A. Grosche, E. Zrenner, M. Pekny, A. Reichenbach, M.W. Seeliger, T. Pannicke, M.T. Perez, Retinal functional alterations in mice lacking intermediate filament proteins glial fibrillary acidic protein and vimentin, FASEB J. 29 (2015) 4815-4828.

[94] Z. Liu, Y. Li, Y. Cui, C. Roberts, M. Lu, U. Wilhelmsson, M. Pekny, M. Chopp, Beneficial effects of gfap/vimentin reactive astrocytes for axonal remodeling and motor behavioral recovery in mice after stroke, Glia 62 (2014) 2022-2033.

[95] M. Pekny, M.J. Porritt, Y. de Pablo, U. Wilhelmsson, Reactive astrocytes, astrocyte intermediate filament proteins, and their role in the disease pathogenesis, in: R. Dermietzel (Ed.), The Cytoskeleton : Imaging, Isolation, and Interaction, Vol. Neuromethods, Springer, 2013, pp. 299-319.

[96] K. Jarlestedt, C.I. Rousset, M. Faiz, U. Wilhelmsson, A. Stahlberg, H. Sourkova, M. Pekna, C. Mallard, H. Hagberg, M. Pekny, Attenuation of reactive gliosis does not affect infarct volume in neonatal hypoxic-ischemic brain injury in mice, PLoS One 5 (2010) e10397.

[97] A. Rolls, R. Shechter, M. Schwartz, The bright side of the glial scar in CNS repair, Nat. Rev. Neurosci. 10 (2009) 235-241.

[98] E.J. Bradbury, L.M. Carter, Manipulating the glial scar: chondroitinase ABC as a therapy for spinal cord injury, Brain Res. Bull. 84 (2011) 306-316.

[99] E.J. Bradbury, L.D.F. Moon, R.J. Popat, V.R. King, G.S. Bennett, P.N. Patel, J.W. Fawcett, S.B. McMahon, Chondroitinase ABC promotes functional recovery after spinal cord injury, Nature 416 (2002) 636-640.

[100] H. Lee, R.J. McKeon, R.V. Bellamkonda, Sustained delivery of thermostabilized chABC enhances axonal sprouting and functional recovery after spinal cord injury, Proc. Natl. Acad. Sci. U. S. A. 107 (2010) 3340-3345.

[101] K. Sharma, M.E. Selzer, S. Li, Scar-mediated inhibition and CSPG receptors in the CNS, Exp. Neurol. 237 (2012) 370-378.

[102] X. Wang, O. Hasan, A. Arzeno, L.I. Benowitz, W.B. Cafferty, S.M. Strittmatter, Axonal regeneration induced by blockade of glial inhibitors coupled with activation of intrinsic neuronal growth pathways, Exp. Neurol. 237 (2012) 55-69.

[103] L.W. Yick, W.T. Wu, K.F. So, H.K. Yip, D.K.Y. Shum, Chondroitinase ABC promotes axonal regeneration of Clarke's neurons after spinal cord injury, Neuroreport 11 (2000) 1063-1067.

[104] V. Menet, M. Prieto, A. Privat, M. Gimenez y Ribotta, Axonal plasticity and functional recovery after spinal cord injury in mice deficient in both glial fibrillary acidic protein and vimentin genes, Proc. Natl. Acad. Sci. U. S. A. 100 (2003) 8999-9004.

[105] K.S. Cho, L. Yang, B. Lu, H. Feng Ma, X. Huang, M. Pekny, D.F. Chen, Re-establishing the regenerative potential of central nervous system axons in postnatal mice, J. Cell Sci. 118 (2005) 863-872.

[106] B.Z. Barkho, H. Song, J.B. Aimone, R.D. Smrt, T. Kuwabara, K. Nakashima, F.H. Gage, X. Zhao, Identification of astrocyte-expressed factors that modulate neural stem/progenitor cell differentiation, Stem Cells Dev. 15 (2006) 407-421.

[107] D.C. Lie, S.A. Colamarino, H.J. Song, L. Desire, H. Mira, A. Consiglio, E.S. Lein, S. Jessberger, H. Lansford, A.R. Dearie, F.H. Gage, Wnt signalling regulates adult hippocampal neurogenesis, Nature 437 (2005) 1370-1375.

[108] Z. Lu, J. Kipnis, Thrombospondin 1-a key astrocyte-derived neurogenic factor, FASEB J. 24 (2010) 1925-1934.

[109] C. Garber, M.J. Vasek, L.L. Vollmer, T. Sun, X. Jiang, R.S. Klein, Astrocytes decrease adult neurogenesis during virus-induced memory dysfunction via IL-1, Nat. Immunol. 19 (2018) 151-161.

[110] H. Song, C.F. Stevens, F.H. Gage, Astroglia induce neurogenesis from adult neural stem cells, Nature 417 (2002) 39-44.
[111] D.A. Laplagne, M.S. Esposito, V.C. Piatti, N.A. Morgenstern, C. Zhao, H. van Praag, F.H. Gage, A.F. Schinder, Functional convergence of neurons generated in the developing and adult hippocampus, PLoS Biol. 4 (2006) e409.

[112] A. Tashiro, V.M. Sandler, N. Toni, C. Zhao, F.H. Gage, NMDA-receptor-mediated, cell-specific integration of new neurons in adult dentate gyrus, Nature 442 (2006) 929-933.

[113] N. Toni, E.M. Teng, E.A. Bushong, J.B. Aimone, C. Zhao, A. Consiglio, H. van Praag, M.E. Martone, M.H. Ellisman, F.H. Gage, Synapse formation on neurons born in the adult hippocampus, Nat. Neurosci. 10 (2007) 727-734.

[114] C. Zhao, E.M. Teng, R.G. Summers Jr, G.L. Ming, F.H. Gage, Distinct morpholo gical stages of dentate granule neuron maturation in the adult mouse hippocampus, J. Neurosci. 26 (2006) 3-11.

[115] A. Sahay, K.N. Scobie, A.S. Hill, C.M. O'Carroll, M.A. Kheirbek, N.S. Burghardt, A.A. Fenton, A. Dranovsky, R. Hen, Increasing adult hippocampal neurogenesis is sufficient to improve pattern separation, Nature 472 (2011) 466-470.

[116] K.G. Akers, A. Martinez-Canabal, L. Restivo, A.P. Yiu, A. De Cristofaro, H.L. Hsiang, A.L. Wheeler, A. Guskjolen, Y. Niibori, H. Shoji, K. Ohira, B.A. Richards, T. Miyakawa, S.A. Josselyn, P.W. Frankland, Hippocampal neurogenesis regulates forgetting during adulthood and infancy, Science 344 (2014) 598-602.

[117] U. Wilhelmsson, M. Faiz, Y. de Pablo, M. Sjoqvist, D. Andersson, A. Widestrand, M. Potokar, M. Stenovec, P.L. Smith, N. Shinjyo, T. Pekny, R. Zorec, A. Stahlberg, M. Pekna, C. Sahlgren, M. Pekny, Astrocytes negatively regulate neurogenesis through the Jagged1-mediated Notch pathway, Stem Cells 30 (2012) 2320-2329.

[118] I. Lebkuechner, U. Wilhelmsson, E. Mollerstrom, M. Pekna, M. Pekny, Heterogeneity of Notch signaling in astrocytes and the effects of GFAP and vimentin deficiency, J. Neurochem. 135 (2015) 234-248.

[119] M. Potokar, M. Kreft, L. Li, J. Daniel Andersson, T. Pangrsic, H.H. Chowdhury, M. Pekny, R. Zorec, Cytoskeleton and vesicle mobility in astrocytes, Traffic 8 (2007) 12-20.

[120] M. Potokar, M. Stenovec, M. Gabrijel, L. Li, M. Kreft, S. Grilc, M. Pekny, R. Zorec, Intermediate filaments attenuate stimulation-dependent mobility of endosomes/ lysosomes in astrocytes, Glia 58 (2010) 1208-1219.

[121] N. Vardjan, M. Gabrijel, M. Potokar, U. Svajger, M. Kreft, M. Jeras, Y. de Pablo, M. Faiz, M. Pekny, R. Zorec, IFN-gamma-induced increase in the mobility of MHC class II compartments in astrocytes depends on intermediate filaments, $\mathrm{J}$. Neuroinflammation 9 (2012) 144.

[122] R. Kinouchi, M. Takeda, L. Yang, U. Wilhelmsson, A. Lundkvist, M. Pekny, D.F. Chen, Robust neural integration from retinal transplants in mice deficient in GFAP and vimentin, Nat. Neurosci. 6 (2003) 863-868.

[123] A. Widestrand, J. Faijerson, U. Wilhelmsson, P.L. Smith, L. Li, C. Sihlbom, P.S. Eriksson, M. Pekny, Increased neurogenesis and astrogenesis from neura progenitor cells grafted in the hippocampus of GFAP-/- Vim-/- mice, Stem Cells 25 (2007) 2619-2627.

[124] J. Middeldorp, W. Kamphuis, J.A. Sluijs, D. Achoui, C.H. Leenaars, M.G. Feenstra, P. van Tijn, D.F. Fischer, C. Berkers, H. Ovaa, R.A. Quinlan, E.M. Hol, Intermediate filament transcription in astrocytes is repressed by proteasome inhibition, FASEB J. 23 (2009) 2710-2726.

[125] Y. de Pablo, M. Chen, E. Mollerstrom, M. Pekna, M. Pekny, Drugs targeting intermediate filaments can improve neurosupportive properties of astrocytes, Brain Res. Bull. 136 (2018) 130-138.

[126] G. Bajic, S.E. Degn, S. Thiel, G.R. Andersen, Complement activation, regulation, and molecular basis for complement-related diseases, EMBO J. 34 (2015) 2735-2757.

[127] T. Iram, Z. Ramirez-Ortiz, M.H. Byrne, U.A. Coleman, N.D. Kingery, T.K. Means, D. Frenkel, J. El Khoury, Megf10 Is a receptor for C1Q that mediates clearance of apoptotic cells by astrocytes, J. Neurosci. 36 (2016) 5185-5192.

[128] P. Gasque, P. Chan, M. Fontaine, A. Ischenko, M. Lamacz, O. Gotze, B.P. Morgan, Identification and characterization of the complement C5a anaphylatoxin recepto on human astrocytes, J. Immunol. 155 (1995) 4882-4889.

[129] A. Ischenko, S. Sayah, C. Patte, S. Andreev, P. Gasque, M. Schouft, H. Vaudry, M. Fontaine, Expression of a functional anaphylatoxin C3a receptor by astrocytes, J. Neurochem. 71 (1998) 2487-2496.

[130] N. Shinjyo, Y. de Pablo, M. Pekny, M. Pekna, Complement peptide C3a promote astrocyte survival in response to ischemic stress, Mol. Neurobiol. 53 (2016) 3076-3087.

[131] S. Sayah, A. Ischenko, A. Zhakhov, A.S. Bonnard, M. Fontaine, Expression of cytokines by human astrocytomas following stimulation by C3a and C5a anaphylatoxins: specific increase in interleukin-6 mRNA expression, J. Neurochem. 72 (1999) 2426-2436.

[132] S. Sayah, A.C. Jauneau, C. Patte, M.C. Tonon, H. Vaudry, M. Fontaine, Two different transduction pathways are activated by C3a and C5a anaphylatoxins on astrocytes, Mol. Brain Res. 112 (2003) 53-60.

[133] S. Nataf, N. Davoust, S.R. Barnum, Kinetics of anaphylatoxin C5a receptor expression during experimental allergic encephalomyelitis, J. Neuroimmunol. 91 (1998) 147-155.

[134] V. Gavrilyuk, S. Kalinin, B.S. Hilbush, A. Middlecamp, S. McGuire, D. Pelligrino, G. Weinberg, D.L. Feinstein, Identification of complement 5a-like receptor (C5L2) from astrocytes: characterization of anti-inflammatory properties, J. Neurochem. 92 (2005) 1140-1149.

[135] Y. Zhang, K. Chen, S.A. Sloan, M.L. Bennett, A.R. Scholze, S. O’Keeffe, H.P. Phatnani, P. Guarnieri, C. Caneda, N. Ruderisch, S. Deng, S.A. Liddelow, C. Zhang, R. Daneman, T. Maniatis, B.A. Barres, J.Q. Wu, An RNA-sequencing transcriptome and splicing database of glia, neurons, and vascular cells of the cerebral cortex, J. Neurosci. 34 (2014) 11929-11947.

[136] M.I. Fonseca, S. Chu, A.L. Pierce, W.D. Brubaker, R.E. Hauhart, D. Mastroeni, 
E.V. Clarke, J. Rogers, J.P. Atkinson, A.J. Tenner, Analysis of the putative role of CR1 in Alzheimer's disease: genetic association, expression and function, PLoS One 11 (2016) e0149792.

[137] P. Gasque, P. Chan, C. Mauger, M.T. Schouft, S. Singhrao, M.P. Dierich, B.P. Morgan, M. Fontaine, Identification and characterization of complement C3 receptors on human astrocytes, J. Immunol. 156 (1996) 2247-2255.

[138] L.E. Clarke, S.A. Liddelow, C. Chakraborty, A.E. Munch, M. Heiman, B.A. Barres, Normal aging induces A1-like astrocyte reactivity, Proc. Natl. Acad. Sci. U. S. A. 115 (2018) E1896-e1905.

[139] S.A. Liddelow, K.A. Guttenplan, L.E. Clarke, F.C. Bennett, C.J. Bohlen, L. Schirmer, M.L. Bennett, A.E. Munch, W.S. Chung, T.C. Peterson, D.K. Wilton, A. Frouin, B.A. Napier, N. Panicker, M. Kumar, M.S. Buckwalter, D.H. Rowitch, V.L. Dawson, T.M. Dawson, B. Stevens, B.A. Barres, Neurotoxic reactive astrocytes are induced by activated microglia, Nature 541 (2017) 481-487.

[140] Y. Shinozaki, K. Shibata, K. Yoshida, E. Shigetomi, C. Gachet, K. Ikenaka, K.F. Tanaka, S. Koizumi, Transformation of astrocytes to a neuroprotective phenotype by microglia via P2Y1 receptor downregulation, Cell Rep. 19 (2017) $1151-1164$.

[141] A.H. Stephan, D.V. Madison, J.M. Mateos, D.A. Fraser, E.A. Lovelett, L. Coutellier, L. Kim, H.H. Tsai, E.J. Huang, D.H. Rowitch, D.S. Berns, A.J. Tenner, M. Shamloo, B.A. Barres, A dramatic increase of C1q protein in the CNS during normal aging, J. Neurosci. 33 (2013) 13460-13474.

[142] A.R. Bialas, B. Stevens, TGF- $\beta$ signaling regulates neuronal C1q expression and developmental synaptic refinement, Nat. Neurosci. 16 (2013) 1773-1782.

[143] B. Stevens, N.J. Allen, L.E. Vazquez, G.R. Howell, K.S. Christopherson, N. Nouri, K.D. Micheva, A.K. Mehalow, A.D. Huberman, B. Stafford, A. Sher, A.M. Litke, J.D. Lambris, S.J. Smith, S.W. John, B.A. Barres, The classical complement cascade mediates CNS synapse elimination, Cell 131 (2007) 1164-1178.

[144] D.P. Schafer, E.K. Lehrman, A.G. Kautzman, R. Koyama, A.R. Mardinly, R. Yamasak, R.M. Ransohoff, M.E. Greenberg, B.A. Barres, B. Stevens, Microglia sculpt postnatal neural circuits in an activity and complement-dependent manner, Neuron 74 (2012) 691-705

[145] G.T. Norris, I. Smirnov, A.J. Filiano, H.M. Shadowen, K.R. Cody, J.A. Thompson, T.H. Harris, A. Gaultier, C.C. Overall, J. Kipnis, Neuronal integrity and complement control synaptic material clearance by microglia after CNS injury, J. Exp. Med. (2018).

[146] V.S. Ten, S.A. Sosunov, S.P. Mazer, R.I. Stark, C. Caspersen, M.E. Sughrue, M. Botto, E.S. Connolly Jr, D.J. Pinsky, C1q-deficiency is neuroprotective against hypoxic-ischemic brain injury in neonatal mice, Stroke 36 (2005) 2244-2250.

[147] V.S. Ten, J. Yao, V. Ratner, S. Sosunov, D.A. Fraser, M. Botto, B. Sivasankar, B.P. Morgan, S. Silverstein, R. Stark, R. Polin, S.J. Vannucci, D. Pinsky, A.A. Starkov, Complement component $\mathrm{C} 1 \mathrm{q}$ mediates mitochondria-driven oxidative stress in neonatal hypoxic-ischemic brain injury, J. Neurosci. 30 (2010) $2077-2087$.

[148] M.G. De Simoni, E. Rossi, C. Storini, S. Pizzimenti, C. Echart, L. Bergamaschini, The powerful neuroprotective action of C1-inhibitor on brain ischemia-reperfusion injury does not require C1q, Am. J. Pathol. 164 (2004) 1857-1863.

[149] J. Mocco, W.J. Mack, A.F. Ducruet, A.A. Sosunov, M.E. Sughrue, B.G. Hassid, M.N. Nair, I. Laufer, R.J. Komotar, M.C.H. Holland, D.J. Pinsky, E.S. Connolly Jr, Complement component C3 mediates inflammatory injury following focal cerebral ischemia, Circ. Res. 99 (2006) 209-217.

[150] F. Bossi, C. Tripodo, L. Rizzi, R. Bulla, C. Agostinis, C. Guarnotta, C. Munaut, G. Baldassarre, G. Papa, S. Zorzet, B. Ghebrehiwet, G.S. Ling, M. Botto, F. Tedesco, $\mathrm{C} 1 \mathrm{q}$ as a unique player in angiogenesis with therapeutic implication in wound healing, Proc. Natl. Acad. Sci. U. S. A. 111 (2014) 4209-4214.

[151] M.E. Benoit, A.J. Tenner, Complement protein C1q-mediated neuroprotection is correlated with regulation of neuronal gene and microRNA expression, J. Neurosci. 31 (2011) 3459-3469.

[152] S.L. Peterson, H.X. Nguyen, O.A. Mendez, A.J. Anderson, Complement protein C1q modulates neurite outgrowth in vitro and spinal cord axon regeneration in vivo, J. Neurosci. 35 (2015) 4332-4349.

[153] H. Lian, L. Yang, A. Cole, L. Sun, A.C. Chiang, S.W. Fowler, D.J. Shim, J. Rodriguez-Rivera, G. Taglialatela, J.L. Jankowsky, H.C. Lu, H. Zheng, NFkappaB-activated astroglial release of complement C3 compromises neuronal morphology and function associated with Alzheimer's disease, Neuron 85 (2015) $101-115$.

[154] J.M. Harder, C.E. Braine, P.A. Williams, X. Zhu, K.H. MacNicoll, G.L. Sousa, R.A. Buchanan, R.S. Smith, R.T. Libby, G.R. Howell, S.W.M. John, Early immune responses are independent of RGC dysfunction in glaucoma with complement component C3 being protective, Proc. Natl. Acad. Sci. U. S. A. 114 (2017) E3839-e3848.

[155] G.R. Howell, D.G. Macalinao, G.L. Sousa, M. Walden, I. Soto, S.C. Kneeland, J.M. Barbay, B.L. King, J.K. Marchant, M. Hibbs, B. Stevens, B.A. Barres, A.F. Clark, R.T. Libby, S.W. John, Molecular clustering identifies complement and endothelin induction as early events in a mouse model of glaucoma, J. Clin. Invest. 121 (2011) 1429-1444.

[156] A.F. Ducruet, B.E. Zacharia, S.A. Sosunov, P.R. Gigante, M.L. Yeh, J.W. Gorski, M.L. Otten, R.Y. Hwang, P.A. Derosa, Z.L. Hickman, P. Sergot, E.S.J. Connolly, Complement inhibition promotes endogenous neurogenesis and sustained antiinflammatory neuroprotection following reperfused stroke, PLoS One 7 (2012) e38664.
[157] F. Wu, Q. Zou, X. Ding, D. Shi, X. Zhu, W. Hu, L. Liu, H. Zhou, Complement component C3a plays a critical role in endothelial activation and leukocyte recruitment into the brain, J. Neuroinflammation 13 (2016) 23.

[158] M.A. Rynkowski, G.H. Kim, M.C. Garrett, B.E. Zacharia, M.L. Otten, S.A. Sosunov, R.J. Komotar, B.G. Hassid, A.F. Ducruet, J.D. Lambris, E.S. Connolly, C3a receptor antagonist attenuates brain injury after intracerebral hemorrhage, J. Cereb. Blood Flow Metab. 29 (2009) 98-107.

[159] N. Davoust, J. Jones, P.F. Stahel, R.S. Ames, S.R. Barnum, Receptor for the C3a anaphylatoxin is expressed by neurons and glial cells, Glia 26 (1999) 201-211.

[160] J. van Beek, M. Bernaudin, E. Petit, P. Gasque, A. Nouvelot, E.T. MacKenzie, M. Fontaine, Expression of receptors for complement anaphylatoxins C3a and C5a following permanent focal cerebral ischemia in the mouse, Exp. Neurol. 161 (2000) 373-382.

[161] A.C. Jauneau, A. Ischenko, P. Chan, M. Fontaine, Complement component anaphylatoxins upregulate chemokine expression by human astrocytes, FEBS Lett. 537 (2003) 17-22.

[162] A.-C. Jauneau, A. Ischenko, A. Chatagner, M. Benard, P. Chan, M.-T. Schouft, C. Patte, H. Vaudry, M. Fontaine, Interleukin- $1 \beta$ and anaphylatoxins exert a synergistic effect on NGF expression by astrocytes, J. Neuroinflammation 3 (2006) 8 .

[163] J. van Beek, O. Nicole, C. Ali, A. Ischenko, E.T. MacKenzie, A. Buisson, M. Fontaine, Complement anaphylatoxin C3a is selectively protective against NMDA-induced neuronal cell death, Neuroreport 12 (2001) 289-293.

[164] Y. Rahpeymai, M.A. Hietala, U. Wilhelmsson, A. Fotheringham, I. Davies, A.K. Nilsson, J. Zwirner, R.A. Wetsel, C. Gerard, M. Pekny, M. Pekna, Complement: a novel factor in basal and ischemia-induced neurogenesis, EMBO J. 25 (2006) 1364-1374.

[165] N. Shinjyo, A. Stahlberg, M. Dragunow, M. Pekny, M. Pekna, Complement-derived anaphylatoxin C3a regulates in vitro differentiation and migration of neural progenitor cells, Stem Cells 27 (2009) 2824-2832.

[166] M.J. Hooshmand, H.X. Nguyen, K.M. Piltti, F. Benavente, S. Hong, L. Flanagan, N. Uchida, B.J. Cummings, A.J. Anderson, Neutrophils induce astroglial differentiation and migration of human neural stem cells via C1q and C3a synthesis, J. Immunol. 199 (2017) 1069-1085.

[167] K. Järlestedt, C.I. Rousset, A. Ståhlberg, H. Sourkova, A.L. Atkins, C. Thornton, S.R. Barnum, R.A. Wetsel, M. Dragunow, M. Pekny, C. Mallard, H. Hagberg, M. Pekna, Receptor for complement peptide C3a: a therapeutic target for neonatal hypoxic-ischemic brain injury, FASEB J. 27 (2013) 3797-3804.

[168] J. Moran, A. Stokowska, F.R. Walker, C. Mallard, H. Hagberg, M. Pekna, Intranasal C3a treatment ameliorates cognitive impairment in a mouse model of neonatal hypoxic-ischemic brain injury, Exp. Neurol. 290 (2017) 74-84.

[169] A. Stokowska, M. Pekna, Complement C3a: shaping the plasticity of the poststroke brain, in: P.A. Lapchak, J.H. Zhang (Eds.), Cellular and Molecular ApprOaches to Regeneration \& Repair, Springer, Cham, 2018, pp. 521-541.

[170] A. Stokowska, A.L. Atkins, J. Moran, T. Pekny, L. Bulmer, M.C. Pascoe, S.R. Barnum, R.A. Wetsel, J. Nilsson, M. Dragunow, M. Pekna, Complement peptide C3a stimulates neural plasticity after experimental brain ischemia, Brain 140 (2017) 353-369.

[171] L.I. Benowitz, W.R. Rodriguez, R.L. Neve, The pattern of GAP-43 immunostaining changes in the rat hippocampal formation during reactive synaptogenesis, Brain Res. Mol. Brain Res. 8 (1990) 17-23.

[172] L.H. Lin, S. Bock, K. Carpenter, M. Rose, J.J. Norden, Synthesis and transport of GAP-43 in entorhinal cortex neurons and perforant pathway during lesion-induced sprouting and reactive synaptogenesis, Brain Res. Mol. Brain Res. 14 (1992) $147-153$.

[173] C.C. Hung, C.H. Lin, H. Chang, C.Y. Wang, S.H. Lin, P.C. Hsu, Y.Y. Sun, T.N. Lin, F.S. Shie, L.S. Kao, C.M. Chou, Y.H. Lee, Astrocytic GAP43 induced by the TLR4/ NF-kappaB/STAT3 axis attenuates astrogliosis-mediated microglial activation and neurotoxicity, J. Neurosci. 36 (2016) 2027-2043.

[174] D. Pavlovski, J. Thundyil, P.N. Monk, R.A. Wetsel, S.M. Taylor, T.M. Woodruff, Generation of complement component C5a by ischemic neurons promotes neuronal apoptosis, FASEB J. 26 (2012) 3680-3690.

[175] G.H. Kim, J. Mocco, D.K. Hahn, C.P. Kellner, R.J. Komotar, A.F. Ducruet, W.J. Mack, E.S. Connolly Jr, Protective effect of C5a receptor inhibition after murine reperfused stroke, Neurosurgery 63 (2008) 122-125 discussion 125-126.

[176] M.C. Garrett, M.L. Otten, R.M. Starke, R.J. Komotar, P. Magotti, J.D. Lambris, M.A. Rynkowski, E.S. Connolly, Synergistic neuroprotective effects of C3a and C5a receptor blockade following intracerebral hemorrhage, Brain Res. 1298 (2009) 171-177.

[177] B. Gong, Y. Pan, W. Zhao, L. Knable, P. Vempati, S. Begum, L. Ho, J. Wang, S. Yemul, S. Barnum, A. Bilski, B.Y. Gong, G.M. Pasinetti, IVIG immunotherapy protects against synaptic dysfunction in Alzheimer's disease through complement anaphylatoxin C5a-mediated AMPA-CREB-C/EBP signaling pathway, Mol. Immunol. 56 (2013) 619-629.

[178] F.H. Brennan, R. Gordon, H.W. Lao, P.J. Biggins, S.M. Taylor, R.J. Franklin, T.M. Woodruff, M.J. Ruitenberg, The complement receptor C5aR controls acute inflammation and astrogliosis following spinal cord injury, J. Neurosci. 35 (2015) 6517-6531.

[179] P.J.C. Biggins, F.H. Brennan, S.M. Taylor, T.M. Woodruff, M.J. Ruitenberg, The alternative receptor for complement component 5a, C5aR2, conveys neuroprotection in traumatic spinal cord injury, J. Neurotrauma 34 (2017) 2075-2085. 